\title{
CUA guideline on the care of the normal foreskin and neonatal circumcision in Canadian infants
}

\author{
Sumit Dave ${ }^{1}$; Kourosh Afshar ${ }^{2}$; Luis H. Braga ${ }^{3}$; Peter Anderson ${ }^{4}$ \\ ${ }^{1}$ Department of Surgery (Urology), Western University, London, ON; ${ }^{2}$ Department of Urologic Sciences, \\ University of British Columbia, Vancouver, BC; ${ }^{3}$ Department of Surgery (Urology), McMaster University, \\ Hamilton, ON; ${ }^{4}$ Department of Urology, Dalhousie University, Halifax, NS; Canada
}

Cite as: Can Urol Assoc J 2017 Dec. 1; Epub ahead of print. http://dx.doi.org/10.5489/cuaj.5033

Published online December 1, 2017

$* * *$

\section{Introduction}

Circumcision is the oldest planned operative procedure in the history of the human civilization but there continues to be a lack of consensus and strong opposing views on whether universal neonatal circumcision should be adopted as a public health measure. The recent American Academy of Pediatrics (AAP) guideline on male circumcision (MC), reversed its prior stand stating that the " health benefits of newborn male circumcision outweigh the risks" and justify access to the procedure if the parents so choose [1]. This recommendation was primarily based on the impressive results from African trials demonstrating the protective effect of MC against Human Immunodeficiency Virus (HIV) and sexually transmitted infections (STI). A review of the literature on MC shows evidence of a vehement debate, often clouded by strong personal biases and lack of high quality evidence. Creation of a guideline specific to the need of Canadian infant males is therefore difficult given the level of evidence provided for each potential benefit, the lack of data directly applicable to the Canadian population, the inability to quantify the true complication rate of routine circumcisions accurately, uncertainty about the health benefits of a circumcision compared with other health interventions, the ethical issues and acceptability of a surgical procedure done by parental consent for future benefits, and the costs of training and implementation of any universal neonatal circumcision policy in Canada.

\section{Acceptance and trends of neonatal circumcision}

Neonatal circumcision rates are declining across several countries including Canada and this may be a reflection of changing demographic patterns and parental beliefs. The Provincial Ministries of Health in Canada indicate circumcision rates of 51-67\% in 1970. In 2009, the Public Health Agency of Canada reported an overall Canadian circumcision 
rate of 31.9\% for 2006-2007 [Public Health Agency of Canada, 2009]. This varied across the provinces with the rate being highest in Alberta (44.3\%) and lowest in Nova Scotia (6.8\%) (www.circinfo.net).

A Centers for Disease Control and Prevention (CDC) report showed a decreasing trend in US circumcision rates from 1999-2000 till 2008-2010 from 60\% to 55\% of newborn males [2]. In the UK between 1997-2004, circumcision rates declined from 2.6/1000 boys/year to 2.1/1000 boys/year [3]. However, a more recent study from the US using the Nationwide Inpatient Sample noted an increasing trend of neonatal circumcisions from $48 \%$ in $1988-1991$ to $61 \%$ in $1997-2000$, reflecting an increase of $6.8 \%$ on average every year [4].

A survey of prospective parents in the US was assessed to obtain parental views of circumcision analyzing the effect of the AAP 1999 circumcision guideline and recent HIV and Human Papilloma Virus (HPV) trials [5]. Individuals with previous circumcised sons, those born in the US and those who discussed circumcision with their partner were more likely to request circumcision. There was no change in support after reading information on recent HIV/HPV trials from Africa. A similar survey in Canada indicated that circumcision status of the father significantly influences the child's circumcision [6]. This study indicates that initial parental views rather than new evidence may continue to be the strongest determinant for neonatal circumcision.

\section{Aims of the review}

The aim of this guideline is to present the current evidence on the benefits of circumcision, the optimal anesthesia/analgesia requirements of neonatal circumcision, the possible complications of circumcision and its effect on sexual function and sensation and the care of a normal foreskin in early childhood. This guideline is directed towards pediatric care- givers who routinely examine and follow male infants, physicians who provide neonatal circumcision services and pediatric urologists and general surgeons. The current guideline is written with the purpose of being applicable to the Canadian population and health care system. The evidence presented is classified according to the Oxford system of evidence-based medicine [7].

The current guideline attempts to answer the following questions:

1. Do the potential benefits of neonatal circumcision justify performing universal neonatal circumcision in Canada?

2. For an individual patient and parent, what are the benefits and risks of a neonatal circumcision and how reliable and applicable is the evidence currently available?

3. What should be the prescribed routine foreskin care in infants, indications for medically indicated circumcision and management of physiological phimosis? 


\section{Methods}

Systematic literature searches were conducted in MEDLINE including Pre-MEDLINE EMBASE, BIOSIS Previews ${ }^{\circledR}$, Web of Science ${ }^{\circledR}$ - with Conference Proceedings, and the Cochrane Central Register of Controlled Trials electronic bibliographic databases and were restricted to either adult or pediatric studies ( $</>18$ years) (2002 to March 2013). All searches were restricted to studies published in English language only.

The search queries were developed using combination of subject headings and free-text terms such as circumcision, circumcision male, uncircumcised, male sexual dysfunction, sexual dysfunction physiological, sexual dysfunctions psychological, erectile dysfunction, sexual problems, sexual arousal disorder, ejaculation dysfunction, sexuality, prostatic neoplasms, prostate cancer, prostate tumor, penile neoplasms, penile cancer, urinary tract infections, phimosis, HIV infections, HIV, human immunodeficiency virus, HPV infections, STI's, using variant spellings and endings. For all searches, editorials, news and letters were excluded. The bibliographies of all relevant retrieved articles and reviews were also examined to identify further relevant articles. A total of 2674 records were identified and after removing duplicate records and excluding non-relevant studies, 229 studies were identified for detailed analysis and included in this analysis.

\section{Care of the normal foreskin in childhood and management of physiological phimosis}

\section{Natural history of the foreskin}

The prepuce arises from the coronal margin by a combination of folding and epithelial outgrowth and has an outer and inner layer separated by Dartos fascia. At birth, the inner foreskin is usually fused to the glans penis and should not be forcibly retracted unless it is possible to retract it with gentle traction. Initial examination of the newborn with a normal prepuce without any ventral deficiency or dorsal hood is usually (except in a baby with a megameatus intact prepuce variant of hypospadias) a reliable indicator that the urethral meatus is in a normal location and rules out significant hypospadias.

The collection of smegma (a white exudate of skin cells and keratin) separating the prepuce from the glans and repeated reflex erections are the primary mechanisms which lead to resolution of physiologic adhesions over time. This process is usually complete by 3 years of age in $90 \%$ of the boys, though this study is a reflection of the poor current data in this regard [8]. In a more recent study from Taiwan the incidence of non- retractable physiological phimosis was $50 \%$ in grade 1 boys and decreased to $35 \%$ in grade 4 and $8 \%$ in grade 7 boys [9].

\section{When does physiological phimosis require treatment?}

In the absence of clinical findings of scarring suggesting pathological phimosis, and history of recurrent urinary tract infections (UTI's) or balano-posthitis, no intervention is 
required for physiological phimosis. Ballooning of the foreskin during voiding is not associated with obstructed voiding and is not an indication for circumcision [10]. Active retraction has the potential to cause micro-tears and lead to scarring and subsequently a true phimosis. Therefore, normal foreskin care in early childhood only starts once the foreskin is retractable and this will happen at varying ages. Once retractable, the child can be taught to gently retract and clean during bathing with normal soap and water. Indications for urological consultation in this age group include suspicion of true phimosis with evident scarring of the preputial ring (Fig 1), genital Lichen sclerosis (Fig 2), recurrent episodes of balanitis (Fig 3) or UTI [4]. If the foreskin is not open by 8-10 years of age, there may be an indication for steroid therapy and gentle retraction, though there is no prescribed, evidence proven age cut-off for this process.

\section{Treatment of physiological phimosis}

Several observational studies and randomized trials have investigated the role of topical steroids and preputial stretching in resolving physiologic phimosis. The key to success with these protocols lies in differentiating physiologic and true phimosis, active counseling and patient selection. Topical steroid aids by thinning the preputial skin and obliterating the stratum corneum, which then allows gentle retraction over time.

\section{Level 1 evidence}

Letendre conducted a randomized double- blind study comparing a 2- month treatment course of emollient cream versus $0.1 \%$ triamcinolone in boys 3-12 years of age [12]. At 4 months, $76 \%$ of those on triamcinolone cream responded as compared to $39 \%$ in the placebo group ( $\mathrm{p}=0.008$ ), with no complications. At 1 year follow up; the success rate in the steroid group had come down to $47 \%$. In another RCT comparing a moderately potent steroid mometasone to moisturizing cream, the authors found a significantly better response rate of $88 \%$ at 8 weeks compared to $52 \%$ in the placebo group [13]. In a randomized double-blinded placebo controlled study using betamethasone, Lund et al showed an initial 74\% cure rate at 4 weeks follow up [14]. At 18 months, 14\% showed a relapse, but none required a circumcision. A lower success rate of $52 \%$ was noted by Nobre et al in an RCT from Brazil using $0.2 \%$ betamethasone-hyaluronidase cream in boys 3-10 years of age [15].

Success rates did not vary by steroid potency as shown by similar foreskin retraction rates using clobetasone (moderately potent steroid, success rate 77\%) compared to betamethasone (highly potent steroid, success rate 81\%) [16]. Side effects are rare and there was no suppression of the hypothalamic-pituitary-adrenal axis provided treatment is not prolonged beyond 8 weeks for each course [17]. 


\section{Level 2-4 evidence}

Zavras et al conducted a prospective study using a mildly potent steroid, fluticasone propionate $(0.05 \%)$, to achieve a $91 \%$ success rate in 1185 boys referred with a diagnosis of phimosis [18]. Long -term success is maintained in over $75 \%$ of the boys following initial success with steroid therapy $[19,20]$. Ku et al noted that success rates were higher in boys $<3$ years of age (92\%) compared to those $\geq 3$ years (70\%), which may reflect compliance or a higher likelihood of pathological phimosis in the older group [21]. Ashfield et al showed a reverse trend of better success rate in older boys, though the result was not found to be statistically significant at any age cut off [22]. Elmore et al showed that topical steroids as an alternative to circumcision are equally effective (74\%) and safe in infants presenting with genitourinary abnormalities and UTI's [23].

Recommendations (care of the normal foreskin and physiological phimosis):

1. Neonatal examination of the foreskin and urethral meatus should be part of routine clinical assessment of all newborn boys. Continued examination of the foreskin without forcible retraction is recommended during yearly physical examinations to rule out pathological phimosis and document natural preputial retraction (Level 5, Grade D).

2. Persistent physiological phimosis in an asymptomatic child should not be an indication for circumcision [Level 5, Grade D].

3. Physiological phimosis requires treatment if associated with true balanoposthitis or recurrent UTI's [Level 5, Grade D]

4. Topical steroids are the first line of treatment for persistent physiological phimosis requiring treatment with good success rates and low risk of complications (Level 1b/2b, Grade A).

5. Moderately- low potency steroid (triamcinolone, clobetasone, hydrocortisone, mometasone) may have similar success compared to a highly potent steroid (betamethasone) (Level 2b, Grade B).

6. Patient selection to ensure compliance, demonstrating the technique of gentle retraction of the foreskin and continued retraction after initial success is important to achieve continued success to topical steroid therapy (Level 5 Grade D).

7. Recurrence of physiological phimosis is common and normally responds to another course of topical steroids (Level 2b/3 Grade C).

Circumcision and risk of urinary tract infections

Prior evidence indicates that neonatal circumcision decreases the risk of urinary tract infections (UTI). The current debate centers on the magnitude of this effect, the overall effect given the low prevalence of male UTI, the lack of high level evidence and the need for a surgical procedure to prevent this risk. The role of circumcision in preventing UTI's 
must be studied in 2 distinct subgroups: males with normal urinary tracts and those with recurrent UTI's or urological conditions predisposing to UTI like vesicoureteric reflux, posterior urethral valves, neurogenic bladders and primary megaureters.

\section{Childhood UTI epidemiology}

Prior data suggest that in boys without predisposing urological conditions, the estimated incidence of UTI in the first 10 years of life varies between 1 to $2 \%$ [24, 25]. The prevalence rate of UTI in symptomatic children is higher. In a meta- analysis of 18 studies, Shaikh et al estimated that in all febrile infants (males and females 0-24 months), the prevalence of UTI was $7 \%$ (95\% CI 5.5-8.4\%) [26]. In older symptomatic children (2-19 years) the prevalence was 7.8\% (95\% CI 6.6-8.9\%). Males under 3 months of age had the highest prevalence of UTI (8.7\%, 95\% CI 5.4-11.9). There was evidence of significant heterogeneity but no publication bias and bagged specimens were included in some studies.

\section{Biological plausibility for the role of circumcision in UTI prevention}

Circumcision prevents UTI by reducing periurethral bacterial colonization secondary to reduced adherence of bacteria to keratinized surfaces and by removing the growth promoting moist preputial environment [27-29]. Foreskin colonization with potential pathogenic bacteria occurs early and leads to an increase in protective Langerhans cells. [30]. In a case control study, circumcision decreased the bacterial colonization of the glans penis for uropathogenic bacteria when compared to boys with an intact foreskin and this effect persisted in older boys [31]. Studies have shown E. coli strains causing UTI in uncircumcised male infants resemble urosepsis strains isolated in adults [32]. In addition, data from the human immunodeficiency virus type 1 (HIV) trial in Uganda showed a decreased prevalence and load of 12 specific anaerobic bacteria following circumcision [27].

\section{Boys with normal urinary tracts}

\section{Level 2 evidence}

In a meta- analysis, among febrile male infants less than 3 months of age, the prevalence of UTI was 10 times higher in uncircumcised males (20.1\% 95\% CI: 16.8-23.4) than circumcised males (2.4\% 95\% CI: 1.4-3.5) [26]. This difference decreased in the 6-12month group (7.3\% and $0.3 \%$ ) and there was no data available beyond infancy.

Translated to likelihood ratios (LR), the uncircumcised male infant (3-24 months old) has a UTI LR of 2.8 versus 0.33 for circumcised males [33]. The risk increases if this infant is of non- black race. Singh-Grewal performed a meta-analysis of 12 published studies (1 RCT, 4 cohort, 7 case-control) on 402,908 children published till 2002 and assuming a $1 \%$ risk of UTI calculated the number of circumcisions required to prevent 1 UTI as 111 
[34]. The quality of the included studies was poor, with variable UTI definitions, bagged specimens in at least 6 studies and potential differential misclassification as 3/4 cohort studies were unable to account for circumcisions past the neonatal period. The overall odds ratio (OR) for a UTI in circumcised males compared to uncircumcised males was 0.13 (95\% CI, 0.07 to 0.23 ). The single RCT by Nayir et al included in this analysis, compared bacteriuria rates between circumcised and uncircumcised boys using bag or mid stream specimens and showed a non-statistically significant OR of 0.13 in the circumcised group (95\% CI, 0.01 to 2.63) [35].

A systematic review conducted by Morris et al, calculated the lifetime risk of a UTI to be $32 \%$ in uncircumcised males compared to $9 \%$ in circumcised males [36]. The authors suggested a NNT of 4.2 (95\% CI 2.2-27) for preventing 1 UTI over a lifetime. A Cochrane review in 2012 failed to identify any new RCT's to include in a meta-analysis [37].

\section{Level 2-4 evidence}

Zorc et al conducted a prospective cross sectional study to identify clinical factors associated with UTI in infants $<60$ days of age [38]. The overall rate of UTI was $9 \%$ and after multivariable adjustment, being uncircumcised was associated with a higher UTI risk (OR 10.4; 95\% CI 4.7-31.4, $\mathrm{p}<0.001$ ). According to a large population- based cohort study conducted in Canada by To et al, the relative risk of UTI requiring hospital admission in uncircumcised compared to circumcised boys was 3.7 (95\% CI, 2.8-4.9) in the first year of life [39]. The number of circumcisions needed to prevent one admission for UTI in the first year of life was 195. In another well- conducted case control study from Australia which included children with urological abnormalities, Craig et al showed that the protective effects of circumcision in reducing risk of UTI extended beyond infancy [40]. In infants, the OR was marginally significant at 0.03 (95\% CI 0.06-1.1). However, the OR for the $>1$ - year group was not statistically significant $(\mathrm{OR}=0.2,95 \%$ CI 0.01-3.7).

The rate of asymptomatic positive urine cultures (bag specimens confirmed with suprapubic aspiration) was significantly lower in a study by Simforoosh et al [41]. None of the 3000 circumcised children followed up to 15-months age had a positive culture while $2 \%$ of the 1000 uncircumcised males had a positive culture. Interestingly, several studies from Israel, where all males undergo a ritual neonatal circumcision, showed a high incidence of post-circumcision UTI [42, 43].

\section{Boys with abnormal urinary tract}

In urological conditions like high grade VUR, posterior urethral valves, primary megaureters the risk of UTI is higher.

Vesicouretric reflux: In a prospective cohort study, Alsaywid et al noted a lower non- significant incidence of new defects on DMSA scans in circumcised males with 
grade IV-V VUR as compared to uncircumcised boys (5.25 versus 10.2\%) [44]. However, 3 of the 4 boys in the circumcised group with new DMSA defects, did not get breakthrough UTI's. Circumcision was more effective than antibiotic prophylaxis alone or anti-reflux surgery in preventing breakthrough UTI (OR 0.9). In contrast after surgical correction of VUR, a concomitant circumcision did not decrease the risk of postoperative UTI [45]. In a small RCT conducted on children $<3$ years with low grade VUR (Grade 1-3), randomized to antibiotic prophylaxis and prophylaxis plus circumcision groups, the authors noted significantly lower positive peri-urethral cultures in the circumcised group up till 9 months of follow up following which results equalized [46]. The authors also showed a significantly lower positive culture rate by urethral catheterization in the circumcised group but did not comment these patients were symptomatic.

Posterior urethral valves: Mukherjee et al showed in a retrospective cross sectional study, that circumcision in boys with posterior urethral valves significantly reduces the incidence of UTI beyond infancy by 83\% [47]. Given that their cohort had a very high incidence of UTI, the NNT to prevent 1 UTI was 1 in boys with valves. UPJ obstruction and antenatal hydronephrosis: In a recent prospective study on infants with antenatally detected hydronephrosis, uncircumcised boys (adjusted OR 3.63, 95\% CI: 1.2-11.2) and females had a significantly higher risk of febrile UTI compared to circumcised males [48].

Roth et al did not demonstrate a protective effect of circumcision in children with grade 3-4 hydronephrosis secondary to UPJ obstruction or obstructive megaureters in a retrospective cohort study [49]. Though unable to show statistical significance, the UTI rate was 0 in circumcised males as opposed to $8.3 \%$ in uncircumcised males. In addition, there is indirect evidence of the protective effect of circumcision in this population when comparing this study (63\% circumcised) which had a 4.3\% UTI rate with a similar cohort presented in a study by Song et al, which had a higher 36\% UTI rate ( $0 \%$ circumcised) [50].

It is unclear whether medical treatment of physiological phimosis or antibiotic prophylaxis can prevent UTI's as effectively as circumcision in this subset of males. Urine specimen collection methodology is an issue and a recent study demonstrated that even catheterized specimens in uncircumcised boys could be contaminated [51]. Studies measuring the incidence of UTI's are intrinsically more difficult to interpret as most measure number of UTI episodes as opposed to number of children with UTI. Assuming a $1-2 \%$ circumcision complication rate and a 1\% UTI risk in normal infants, universal neonatal circumcision cannot be justified based on a number needed to treat (NNT) of 111 [34]. Even if we accept a lower complication rate of $0.2 \%$ and a $2 \%$ UTI risk, given the effectiveness of UTI treatment, 6 UTI's will be prevented at the expense of 1 circumcision complication. This equation changes in the favor of a circumcision in those 
with recurrent UTI (assuming a risk of 10\%, the NNT is 11) and boys with urological abnormalities (even assuming a inflated risk of UTI with VUR being 30\%, the NNT is 4) [34].

\section{Recommendations (MC and UTI prevention):}

1. Neonatal circumcision decreases the risk of UTI (Level 2a).

2. The risk of UTI is low in infant males and decreases further beyond infancy (Level 2b-4).

3. There is paucity of level-1 evidence to justify recommending universal circumcision to prevent UTI's in normal males.

4. A stronger effect of neonatal circumcision in preventing UTI's in boys with urological abnormalities has been demonstrated and therefore it is recommended that a discussion with the parents is advisable for this subgroup of neonates (Level 3-4 Grade C).

\section{Circumcision and risk of sexually transmitted infections}

A decreased risk of HIV and other STI's is the primary argument driving a change in risk-benefit assessment of male circumcision. The other benefits of MC are overshadowed to a large extent by its effect on HIV and STI's and therefore data in relation to these benefits must be scrutinized carefully to obtain evidence- based recommendations.

\section{Circumcision and HIV prevention}

\section{Epidemiology of HIV infections}

A recent Public Health Agency of Canada report estimated a HIV prevalence rate of 208 per 100,000 population, with an $11.4 \%$ increase compared to 2008 estimates [52]. Men who have sex with men (MSM) accounted for $47 \%$ of prevalent infections followed by intra-venous drug users (17\%) and heterosexual individuals (17.6\%).

Based on RCT's conducted in HIV high prevalence sub-Saharan Africa, there is clear Level 1 evidence that male circumcision reduces the risk of HIV infection in heterosexual men, in that region of the world [53-55]. In 2007, the WHO and UNAIDS recommended MC, regardless of HIV serostatus, as an additional intervention in countries with predominant heterosexually acquired HIV infection, where HIV is prevalent and circumcision rates are low [56]. Circumcision should not replace promotion of the "ABC” (Abstinence, Behavior change and correct and consistent Condom use) strategy or value of voluntary counseling and testing and care services for STI's. The CDC convened a Consultation on Public Health Issues Regarding Male Circumcision in the United States For Prevention of HIV Infection in 2007 and put forward the following key proposals [57]: 
1. With respect to HIV prevention, MC is one of several partially effective riskreduction alternatives for heterosexual men that should be used in combination with other measures.

2. There is no need or equipoise to conduct a US trial of MC for HIV prevention among men who have sex with women.

3. There is not enough evidence to make a recommendation for MC for MSM to prevent HIV infection and there may be equipoise to conduct an efficacy trial for this population.

4. For newborns, medical benefits outweigh risks and the benefits and risks should be explained to parents.

\section{Role of prepuce in HIV infection}

The protective effect of circumcision against HIV infection has been attributed to several factors. Microabrasions during intercourse may provide easier access to the virus and the likelihood of such coital trauma is higher in those uncircumcised [58]. The inner foreskin mucosa has a higher density of Langerhans cells for which HIV-1 demonstrates specific tropism in in-vitro studies [59]. Circumcision removes a majority of foreskin Langerhan cells. Pro-inflammatory anaerobes, which are supported by the anoxic microenvironment of the intact foreskin, also contribute to viral survival [60]. The lack of keratinization especially of the inner foreskin compared to a circumcised penis may also aid HIV infection [61]. In a sub analysis in the control group of the Ugandan RCT, foreskin surface area was predictive of the risk of HIV acquisition [62]. Men with the largest foreskin surface area had a 2 times higher incidence rate compared to those with the lowest quartile surface area.

In addition, higher rates of STI, such as herpes simplex virus -2 (HSV-2) and genital ulcer disease (GUD), increases susceptibility to HIV infection and circumcision may decrease HIV risk by these intermediate factors but this relationship is complex and bidirectional [63-66].

\section{Female to male HIV transmission}

\section{Observational studies}

Following the first observational study in 1986 suggesting a decreased risk of HIV in circumcised men, several studies and a meta-analysis of 15 observational studies conducted in 2000, supported a protective effect of circumcision against HIV infection (adjusted RR 0.42, 95\% CI 0.34-0.54\%) [67, 68]. More recently, Warner et al conducted a cross sectional study among heterosexual African American men and analyzed the protective effects of MC in a group of men with known HIV exposure [69]. Circumcision was associated with a 51\% reduction in HIV prevalence among the 394 visits by men who were exposed to HIV positive female partners (adjusted PRR 0.49, 95\% CI 0.26- 
0.93). In contrast, when the HIV exposure was unknown, circumcision status was not protective (adjusted PRR 1.00, 95\% CI 0.86-1.15). A global epidemiological study in 118 countries concluded that circumcision was associated with a lower HIV rates, independent of religion [70]. However, for non-sub-Saharan countries with a primarily homosexual or IV drug use modality of HIV transmission, circumcision status was not associated with a lower risk of HIV infection.

\section{Meta-analysis of HIV RCTs}

A Cochrane review of the 3 trials (Table 1) concluded that medical circumcision reduces the acquisition of HIV by heterosexual men between 38-66\% over 2 years, with an incidence risk ratio of 0.5 (95\% CI $0.34-0.72)$ at 1 year and 0.46 (95\% CI 0.34-0.62) at 2 years follow up in the circumcised group compared to the non-circumcised group [71]. There was no evidence of heterogeneity $\left(\mathrm{I}^{2} 0 \%\right)$. With a low assumed control risk of $1 \%$ (10 per 1000 population over a 2-year period), the number needed to treat (NNT) based on this meta-analysis was 186 . The combined per protocol analysis showed a stronger protective effect (IRR 0.34, 95\% CI 0.24-0.47).

The possibility of behavioral disinhibition, leading to unsafe sexual practices, can potentially offset the protective effect of circumcision and this effect may be dependent on the timing of circumcision [72]. The South African trial evaluated behavioral aspects post circumcision and noted a higher mean number of sexual contacts in the circumcised group compared to the uncircumcised group [55]. The Kenyan trial also showed a statistically significant difference in the circumcised versus uncircumcised group with respect to unprotected sexual intercourse and consistent condom usage [53]. The Ugandan RCT did not find this difference even on long-term follow up [54, 73]. In a comprehensive analysis of 1309 men enrolled in the Kenyan RCT, Mattson et al evaluated risk compensation using a self-validated 18 item risk propensity score and acquisition of other STI's as a marker of risk behavior [74]. Men in this study were not clearly informed that MC reduced HIV risk and both groups received intensive counseling. STI risk was higher in the circumcised group at baseline and incident STI was higher at 6-month follow up. There was no difference in the risk scores at 6 and 12 month follow up in the 2 groups.

\section{Male to male transmission}

According to CDC estimates in 2006, of 56300 new HIV infections in the US, 53\% were in men who have sex with men (MSM) males [75]. Heterosexual transmission was responsible in 31\% cases. Canadian estimates are similar with more than 50\% of new infections occurring in MSM males.

Evidence of an association between circumcision status and HIV infection in men who have sex with men (MSM) is limited to observational studies, not usually stratified by receptive and insertive roles. It is believed that men who practice an insertive role 
during anal intercourse would likely benefit from MC while those who perform a receptive role have little or no protection. Most MSM are likely to be infected through a receptive rather an insertive role, which would further dilute the effects of MC in this population. In a Cochrane review by Wiysonge et al, including 21 observational studies (6 cohort, 14 cross-sectional, 1 case-control; 71,693 participants) were analyzed to assess the impact of circumcision for preventing HIV infection in MSM males the risk for HIV acquisition was not associated with MC (OR 0.86, 95\% CI 0.7-1.06) [76]. In a subgroup analysis of men reporting an insertive role, MC was found to be protective (3465 participants; OR $0.27,95 \%$ CI 0.17-0.44). The overall quality of the studies included was poor with high risk of attrition and detection bias. A previous meta- analysis by Millett et al in 2008 had also reported a similar non- significant RR of 0.86 amongst all MSM men and a trend towards lower HIV risk in MSM men who practiced an insertive role (RR 0.70, 95\% CI 0.2-2.2) [77].

Londish et al created a mathematical model incorporating circumcision and seropositioning in the MSM population to predict the reduction in HIV prevalence and incidence [78]. The authors predicted that in a developed country with $10 \%$ HIV prevalence, with universal circumcision, it would take 20 years to reduce HIV incidence by $5 \%$ compared to pre-intervention levels and prevalence to $9.6 \%$.

\section{Male to female transmission}

MC can potentially decrease female partner HIV infection by a direct effect, or indirectly (over 10-20 years) at the population level by reducing the overall male prevalence.

The Ugandan RCT enrolled 92 couples in the circumcised group and 67 in the control group to study the direct effects of MC in HIV positive men on female partner HIV status over a 24 month follow up [79]. This trial was underpowered and terminated early since recruitment was futile. No evidence of protection was identified (adjusted HR 1.49, 95\% CI 0.62-3.57). A meta-analysis of 7 longitudinal population based studies including the Ugandan trial did not show any protective effect on female partners of circumcised males (RR 0.80, 95\% CI 0.54-1.19) [80]. There was evidence of between study heterogeneity with studies showing reverse effects. In a prospective cohort study based on an RCT, conducted to assess HSV 2 suppression impact on HIV transmission, conducted in Africa 1096 serodiscordant couples were followed for a 18 month period [81]. Circumcision was associated with a $40 \%$ lower risk of HIV transmission to female partners though the results were not statistically significant (HR 0.62, 95\% CI 0.35-1.10).

\section{Conclusions on the benefit of neonatal circumcision in preventing HIV}

There are several factors, which have to be considered when adopting findings from recent evidence as a basis for recommendation of neonatal circumcision in more developed countries [82-87]. The large sample size, magnitude of the effect, consistent results across the 3 trials and meta-analyses, and sound statistical methods to address 
confounding factors are the primary strengths of these well conducted trials, which upholds the internal validity of the results to a large extent barring some concerns. These concerns include early trial stoppage, inadequate allocation concealment and random sequence generation, and risk of attrition bias [71, 82]. The primary issue in interpreting these results relates to external validity of these trials in the Canadian setting.

1. The MC rate in the 3 African trial sites ranged between $10-20 \%$ and HIV prevalence in these countries was between $7-25 \%$ (incidence $1.7-1.8 \%$ per year). In contrast, in Canada the MC rate is around 35\% and HIV prevalence is much lower and this would lead to a substantially higher number needed to treat.

2. A difference in the modes of HIV transmission and baseline neonatal circumcision rates affects the available susceptible population, which will be protected by MC. Only a small proportion of HIV transmission is due heterosexual activity and men who have sex with men is a group not protected by MC.

3. Variations in sexual practices and behavior (including condom usage), and differences in STI prevalence will also alter the protective effects of MC.

4. Access to health care and earlier detection and treatment for HIV infected males and HPV vaccination programs may also modify the observed protective effects.

5. Ethical considerations of parental consent and racial/ethnic acceptability further complicate the issue when implementing universal circumcision programs.

6. Cost benefit analysis compared to alternative preventive strategies, should be considered and studied in a Canadian context to allow generation of a clear recommendation [87].

7. The trials were all conducted in sexually active adult men from HIV endemic areas in Africa who were motivated and interested in a free circumcision. They also received counseling as part of trial. This will result in overestimation of the protective effect, different from a more real-world setting.

8. In addition, the long- term effectiveness beyond 2 years follow up is currently only published for the Ugandan trial [73].

Recommendations (MC and HIV protection):

1. Female to male transmission: There is compelling evidence that MC reduces the risk of $\mathrm{HIV}$ transmission from female partners to male (Level 1 A evidence, Grade A recommendation). The magnitude of the effect is debatable and cannot be extrapolated to Canada from the African RCT's.

2. Male to male transmission: Based on current evidence, MC does not provide protection for men who have sex with men (Level 2a evidence).

3. Women partners: Based on current evidence, $\mathrm{MC}$ is not protective for female partners (Level 2a-b evidence). 


\section{Universal infant circumcision cannot be recommended to prevent HIV infection based on current evidence (Grade B).}

\section{Circumcision and human papilloma virus (HPV) prevention}

Human papilloma virus (HPV) is the commonest STI worldwide and of the more than 100 types, about 40 can infect the ano-genital area. In the absence of vaccination, up to 75\% of Canadians would have at least one lifetime HPV infection [www.phacaspc.gc.ca]. High- risk oncogenic types like 16 and 18 are implicated in cervical, penile, vulval, vaginal, anal and some oropharyngeal cancers while low risk non-oncogenic subtypes like 6 and 11 cause genital warts. The effect of circumcision on HPV is difficult to interpret as HPV infection can be transient, affect multiple genital areas outside the foreskin, include several high risk and non-high-risk types and is significantly associated with other behavioral confounders. In addition, HPV prevalence, incidence, clearance and viral load are all potential outcomes, which can be studied and have differing health implications.

\section{HPV in men}

\section{Level 1-2 evidence}

Auvert et al showed a reduction in the prevalence of urethral high- risk HPV infection following male circumcision with a prevalence rate ratio of 0.68 (95\% CI 0.52-0.89, $\mathrm{p}=0.002$ ) in circumcised men as compared to uncircumcised men [88]. Significantly, the prevalence differences between the 2 groups were not significant for HPV type 16 but were for HPV type 18.

Six secondary trials analyzed HIV positive and negative men enrolled in the Ugandan HIV trial with regards to HPV prevalence, acquisition/incidence, clearance and viral load [89-94]. The first trial investigated the prevalence of HPV in a subgroup of participants and only included samples from the glans and coronal sulcus, a factor for possible bias due to differential infection sites in circumcised males [89, 95]. The adjusted risk ratio for prevalence of high risk HPV at 2 years follow up in the circumcised group was 0.65 (95\% CI 0.46-0.90, $\mathrm{p}=0.0009)$ and 0.66 for low risk HPV genotypes (95\% CI 0.49-0.91, $\mathrm{p}=0.01)$. In a subsequent report, the same group showed that the 1- year penile shaft HPV prevalence after MC was not statistically significant lower in the circumcised group (adjusted PRR 0.66, 95\% CI 0.39-1.12, p=0.12) [90]. The third trial evaluated HPV acquisition and clearance in HIV negative men using glans and coronal sulcus samples [91]. The incidence rate of HR-HPV infection was statistically significant at 1 year (Incidence rate ratio $=0.61,95 \%$ CI $0.44-0.85$ ) in the uncircumcised group but at 2 years follow up the effect was not statistically significant (IRR=0.64, 95\% CI 0.38-1.07). The incidence of type specific HR HPV was statistically significant for only the 18 and 33 genotypes and not 16 . The acquisition of new multiple 
infections was lower in the circumcised group (IRR 0.45, 95\% CI 0.28-0.73) compared to the non-circumcised group. Clearance rates per 100 person years were statistically significant only for types 39, 51 and 58 and overall clearance rates were higher in the circumcised group ( $\mathrm{RR}=1.36,95 \%$ CI 1.13-1.63). The fourth study in the Ugandan trial evaluated HR HPV prevalence, acquisition/incidence and clearance in HIV positive married men with or without a circumcision [92]. A random sample comprising $22 \%$ of those enrolled was tested at enrollment and at 24 months follows up. MC provided partial protection with the circumcised group (55\% positive) showing lower HR-HPV prevalence at 24 months ( $\mathrm{PRR}=0.77,95 \% \mathrm{CI} 0.62-0.97$ ). The incidence rate for one or more new infections after adjustment was not statistically significant between the circumcised and non-circumcised group (IRR 0.74, 95\% CI 0.54-1.01), however the proportion of men acquiring multiple new HR-HPV infections was lower in the circumcised group (IRR 0.40, 95\% CI 0.19-0.84). The clearance rate of HPV infections was not significant different between the 2 arms. In a more recent analysis of 999 men (HIV positive and negative) from the Ugandan trial, Tobian et al showed an increased HPV clearance in HIV negative circumcised men (adjusted RR 1.48, 95\% CI 0.55-0.89) and lower incidence of HR-HPV acquisition in HIV positive men (IRR 0.70, 95\% CI 1.67-2.44) [93]. The final study evaluated HPV viral load in circumcised and uncircumcised HPV infected men at 24 months [94]. MC decreased HPV viral load in circumcised compared to uncircumcised men for new infections acquired after enrollment but the results were statistically significant for only serotype $16(\mathrm{p}=0.001)$.

Two meta-analyses were conducted evaluating the effect of MC on HPV [96, 97]. Albero et al in 2012 analyzed data from 14 observational studies and 2 RCTs conducted between 1971 and 2010 [97]. Accepting heterogeneity in MC reporting status, sites sampled and methods of detection, in the 1784 participants analyzed with data from the 2 RCT's, the authors detected a strong inverse association between circumcision and highrisk HPV prevalence with an OR of 0.67 (95\% CI 0.54-0.82). The 14 prevalence studies showed a similar pooled result of overall HPV prevalence (OR 0.57, 95\% CI 0.42-0.77). HPV prevalence remained lower in circumcised men even pooling studies where the penile shaft or scrotum was sampled. There was no association found between circumcision and new genital HPV infections or clearance. A previous meta-analysis conducted by Larke et al till 2010, also showed similar prevalence results (OR 0.57, 95\% CI 0.45-0.71) [96]. This prevalence difference diminished at sites away from the glans and urethra. There was weak evidence that circumcision was associated with decreased HPV incidence (RR 0.75, 95\% CI 0.57-0.99) or clearance (RR 1.33, 95\% CI 0.89-1.98).

\section{Level $2 c-4$ evidence}

The evidence in regards to effectiveness of circumcision in prevention of HPV transmission is contradictory when assessing observational and ecological studies. 
Dickson et al followed 450 children from birth in a cohort study conducted in New Zealand up to 32 years of age with circumcision status reported by mothers at 3 years of age [98]. Sexual behavior was recorded at 21, 26 and 32 years along with assessment of socioeconomic and moral-religious emphasis of family. Seropositivity for HPV 16 or 18 at 32 years was lower in the uncircumcised group (Adjusted OR 1.4, 95\% CI 0.85-2.2) but more associated with lifetime number of partners and moral-religious emphasis of the family of origin. Albero et al reported on 3969 participants from 3 countries followed over 4 years and used coronal sulcus/glans, penile shaft and scrotal swabs to compare HPV prevalence in circumcised and non-circumcised males [99]. A multivariable analysis adjusting for race, marital status, lifetime female sexual partners, female sexual partners in 3-6 months and male sexual partners in the past 3 months did not find any association between MC and oncogenic HPV (PR 0.95, 95\% CI 0.87-1.03). MC was significantly associated with a decreased risk of non-oncogenic HPV infection.

Circumcision was associated with a significantly lower HPV 16 seroincidence in MSM males reporting an insertive role during sex (Adjusted HR 0.47, 95\% CI 0.28-0.98, $\mathrm{p}=0.043)[100]$.

\section{HPV in female partners}

Two trials conducted on HIV positive and negative men in Uganda analyzed transmission of HPV to female partners [101, 102]. The implications of reduced HPV infection in female partner cervical cancer rates are not clearly discernible since there are several other confounding risk factors.

In the first trial on HIV negative men and their partners, the year- 2 prevalence of HR-HPV infection in partners was 28\% in the circumcised group and $39 \%$ in the uncircumcised group (PRR 0.72, 95\% CI 0.60-0.85) [101]. The incidence of any HRHPV infection between 0 and 2 years was also lower in the circumcised group female partners (IRR 0.77, 95\% CI 0.63-0.93). In terms of specific HR genotypes, the results were specifically not statistically significant for HR-HPV 16 or 18 . The clearance rate for all genotypes was $66 \%$ in the circumcised group partners as opposed to $59 \%$ in the uncircumcised partners $(\mathrm{p}=0.014)$. This clearance rate was reversed for HPV 16 with the uncircumcised group having a $74 \%$ clearance rate versus $52 \%$ in the circumcised group (RR 0.70, 95\% CI 0.54-0.92). In a second trial on female partner HPV infection, Tobian et al studied the effect of MC in HIV infected men [102]. Circumcision status in male partners was not associated with lower HR-HPV prevalence in female partners (PRR=1.07, 95\% CI 0.86-1.32, $\mathrm{p}=0.64)$ or lower HR-HPV incidence over 2 years $(\mathrm{IRR}=1.05,95 \% \mathrm{CI} 0.77-1.43)$ or clearance rates $(\mathrm{RR}=0.96,95 \% \mathrm{CI} 0.83-1.11)$. 


\section{Alternative strategies in HPV prevention}

The benefit of MC on HPV infection dynamics has to be analyzed in the presence of complimentary HPV vaccination, protection offered by routine condom usage and other safe sexual practices. HPV vaccination is currently available and recommended for males (HPV 4 vaccine, 9-26 years of age), females (HPV 2 or 4 vaccine, 9-13 years and 14-26 years of age) and MSM (HPV 4 vaccine, >9 years of age) with good evidence (Level 1 evidence, Grade A recommendation) of its effectiveness and safety [National Advisory Committee on Immunization, HPV guideline 2007]. A prospective cohort study showed that correct and consistent condom usage also decreased risk of HPV transmission by $70 \%$ in young newly sexually active women [103].

\section{Recommendations (MC and HPV infections)}

1. HPV prevalence in men: Current evidence suggests a modest decrease in HPV prevalence in the glans and coronal sulcus up to 2 years following MC. (Level $1 \mathrm{~b}$ evidence). The protective effect is partial, does not cover all high- risk types and is weaker further away from the glans and coronal sulcus. It is not clear whether this effect will persist into adulthood following neonatal circumcision.

2. HPV clearance in men: There is no evidence (except a single RCT on HIV negative men) that MC increases HPV clearance (Level 1b-2b evidence). If it did increase clearance this may also inflate the impact of the prevalence benefits mentioned.

3. HPV incidence or acquisition in men: There is no convincing evidence to suggest that MC decreases HPV acquisition or incident infections in HIV positive or negative men (Level 1b-2b evidence).

4. HPV in female partners: MC lowers prevalence and incidence in partners of HIV negative men and improves clearance rates (Level 1b2b).

5. As a public health intervention, it is likely that the effect of HPV vaccination and behavioral modification will be more effective than performing universal neonatal circumcisions on all males (Grade B).

\section{Circumcision and non-ulcerative STI prevention}

The most common non- ulcerative STIs are Gonorrhea, Chlamydia and Trichomonas infections. Chlamydia is the most commonly diagnosed bacterial STI with approximately 65000 cases reported in Canada in 2006. These STI's are initiated by bacterial binding to a variety of host receptors and unlike HIV a biological explanation of how circumcision can be protective against these infections is lacking.

Two RCTs have addressed the role of MC in these infections. In the Kenyan study, there was no association between circumcision status and non-ulcerative STIs but 
condom usage was protective (HR 0.64, 95\% CI 0.50-0.82) [104]. The Orange Farm study showed lower Trichomonas vaginalis infection in men only in an as-treated analysis (Adjusted OR 0.47, 95\% CI 0.25-0.92) [105]. A meta-analysis of 30 observational studies failed to identify a statistically significant association between nonulcerative STI's and MC [106].

In a prospective multi-center, U.S. study involving 2021 men there was evidence for a statistically non-significant increased prevalence and incidence of gonorrheal infection in non-circumcised men (odds ratio 1.3, 95\%CI 0.9-1.7 and 1.6, 95\% CI 1.02.6) but no difference with respect to Chlamydia infection [107]. In another prospective study, uncircumcised male partners had a higher risk of $\mathrm{T}$ vaginalis infection compared to circumcised partners of T vaginalis infected women (OR 1.8, 95\% CI 1.1-3.2) [108]. Mycoplasma genitalium can cause urethritis, cervicitis and pelvic inflammatory disease. Multivariate analysis of data collected in the Kenyan HIV trial, showed a higher likelihood of M genitalium infection in non-circumcised men (adjusted OR 0.54, 95\% CI 0.29-0.99) [109]. Washing the penis within the first hour after sex had a protective effect. In a prospective cohort study, circumcision did not seem to have any protective effect on female partners with regards to chlamydial, gonococcal and trichomonal infections [110].

\section{Recommendations (MC and non-ulcerative STI's):}

1. Currently, there is no significant evidence to support the protective role of $\mathrm{MC}$ in the acquisition of non-HPV, nonulcerative STIs (Level 2a-b evidence, Grade B recommendation).

\section{Circumcision and prevention of genital ulcer disease (GUD) and ulcerative STIS}

HSV 1 and 2, T pallidum (syphilis), H ducreyi (chancroid) and K granulomatis (Donovanosis) are the common causes of genital ulcer disease (GUD) with HSV infections accounting for $70-80 \%$ of the infections leading to a genital ulcer [Public Health Agency of Canada]. The true incidence of HSV 1 and 2 is unknown but these infections are very common with estimates based on serological tests suggesting at least 20\% prevalence in Canada [Public Health Agency of Canada]. Chancroid is extremely rare in Canada and acquisition is primarily limited to endemic areas. Previously rare in Canada, the incidence of syphilis has shown an increase especially in MSM males and sex workers.

Women and men with GUD and HSV-2 have a higher risk of acquiring or transmitting HIV and conversely HIV infection increases the risk of GUD [111, 112]. Observational studies suggest that prevalent HSV-2 infection leads to a 2-3fold increase in the risk of HIV acquisition and this risk increases up to 7-fold with incident HSV-2 infection [113, 114]. In a HIV vaccine trial (Step study) conducted in MSM men, HSV-2 infection was an important risk factor for HIV acquisition amongst vaccine and placebo recipients (HR 2.2, 95\% CI 1.4-3.5) [115]. It is likely that the correlation between these 
two infections is due to high-risk sexual behavior making it unclear whether HSV-2 acquisition is an important direct cofactor for HIV infection [116-118].

\section{HSV}

Condom usage has a limited role in preventing HSV transmission with a $50 \%$ protective rate for male to female transmission. Unlike HIV, HSV transmission is less dependent upon the presence of foreskin mucosa.

\section{Level 1-2 evidence}

In the Ugandan RCT, which included HIV positive men, Tobian et al showed a lower risk of HSV 2 seroconversion in the circumcised group over 2-years follow-up (Adjusted IRR 0.70, 95\% CI 0.55-0.91) [118]. Consistent condom usage had a slightly higher protective effect (Adjusted IRR 0.56, 95\% CI 0.36-0.89). In a second analysis of the Ugandan RCT with HIV negative men, the partial protective effect of MC against HSV-2 seroconversion was similar [89]. Multivariate analysis of South African RCT data, did not show a protective effect for MC against HSV-2 seroincidence (IRR 0.68, 95\% CI $0.38-1.22$ ) but the effect was reversed in an as treated analysis presumably due to a $8.2 \%$ crossover rate (IRR 0.45, 95\% CI 0.24-0.82) [63].

Mehta et al conducted an RCT in Kenya to assess the protective effect of circumcision against HIV, HSV-2 and GUD [65]. HSV-2 incidence did not differ by circumcision status (RR=0.94, 95\% CI 0.7-1.25) but HSV-2 incident infection tripled the risk of HIV acquisition (risk ratio 3.44, 95\% CI 1.52-7.80). Moreover, non HSV-GUD risk was reduced by $50 \%$ in those circumcised (RR 0.52, 95\% CI 0.37-0.73). In a multivariable model, the presence of GUD was associated with a 7 times greater risk of HIV seroconversion, suggesting that the protective effect of circumcision may be partially be mediated by reducing the risk of GUD. More than 50\% of HIV seroconversions were preceded by HSV-2 or GUD.

\section{Level 2-4 evidence}

In a meta-analysis of observational studies, $\mathrm{MC}$ was not associated with a decreased risk of HSV-2 seropositivity (RR 0.88, 95\% CI 0.77-1.01) and this effect was less protective when restricting the analysis to studies using genital examination rather than self reported circumcision status (RR 0.97, 95\% CI 0.80-1.17) [106]. There was a protective effect of MC on syphilis seropositivity (RR 0.67, 95\% CI 0.54-0.83) though there was significant heterogeneity amongst the studies and 2 of the largest studies included in this analysis showed the least protective effects. A definitive conclusion could not be reached for the risk of chancroid with the adjusted RR varying between 0.13-1.11.

$\mathrm{Xu}$ et al estimated the prevalence of circumcision in the US and examined the association between MC and HSV-2 infection using the National Health and Nutrition 
Examination survey conducted on 6174 men [119]. HSV-2 infection was associated with age, race and sexual behaviors but not with circumcision status (OR 1.1, 95\% CI 0.8-1.5).

\section{Male to male HSV-2 transmission}

In an observational study on 3828 men, Jameson et al found that, even in men reporting primarily an insertive role, MC was not protective against HSV-2 (Adjusted OR 0.66, 95\% CI 0.27-1.63) [120]. Barnabas et al conducted a cross sectional study on MSM males and found that MC was associated with a borderline protective effect against HSV2 infection (OR 0.7, 95\% CI 0.5-1.0) [114]. In a Cochrane review of MSM males, circumcision did not have a protective role in preventing syphilis (OR 0.96, 95\% CI 0.821.13) or HSV-2 infections (OR 0.86, 95\% CI 0.62-1.2 [77]. In developed countries, the results of MC can be contradictory, with opposite direction of the effect shown in 2 longitudinal cohort studies from New Zealand [121, 122].

Non-ulcerative and ulcerative STIs in female partners

Gray et al conducted a sub trial in the Ugandan HIV RCT on 1563 HIV negative women married to men randomized to circumcised and non-circumcised groups followed for a year [123]. Adjusted analyses suggested a 22\% circumcision efficacy for GUD (Adjusted PRR 0.78, 95\% CI 0.61-0.99), a 45\% efficacy for trichomonas (Adjusted PRR 0.55, 95\% CI 0.34-0.89) and a weak 18\% efficacy for bacterial vaginosis (BV) (Adjusted PRR 0.82, 95\% CI 0.74-0.91). In the Ugandan RCT on HIV negative men, MC did not reduce the risk of HSV-2 acquisition in women partners of both HSV-2 negative and positive male partners [124]. In addition, in a 2008 prospective study of almost $6000 \mathrm{HIV}$ negative women showed no difference in female acquisition of Chlamydia (adjusted HR 1.25, 95\% CI 0.96-1.63), gonorrhea (adjusted HR 0.99, 95\% CI 0.80-1.36) or T. Vaginalis (adjusted HR 1.05, 95\% CI 0.80-1.36) according to circumcision status [110].

\section{Recommendations (MC and ulcerative STI's):}

1. Currently, there is no significant evidence to support the protective role of universal neonatal circumcision for males and females in the acquisition of ulcerative STI's (Level 2-4 evidence, Grade C recommendation).

2. There is weak evidence of decreased seroconversion for HSV-2 following MC in adult men in Africa (Level 2a-b).

\section{Circumcision and risk of penile cancer}

\section{Epidemiology}

Penile cancer is a rare disease with age standardized incidence rates of 0.3-1.0 per 100,000 men in Europe and North America, accounting for $0.4-0.6 \%$ of all malignancies [125]. The potential risk factors for penile cancer include phimosis and balanitis, 
smoking, HPV infections, penile oral sex, Lichen sclerosis, premalignant conditions like Bowen's disease and erythroplasia of Queyrat, priapism, urethral stricture and PUVA therapy [126-128]. Therefore, MC for preventing penile cancer is possibly one of the several preventive interventions, which still does not account for a host of risk factors [127-129]. The International Consultation on Urologic Disease 2009 consensus publication on penile cancer prevention advocated smoking cessation as a Grade C recommendation while male HPV vaccination and universal circumcision were not recommended [128].

\section{Biological plausibility}

Penile cancer is mediated through 2 mechanisms; HR HPV infections and a subset through non- HPV mediated mechanisms related to phimosis and Lichen Sclerosus. Oncogenic HPV (mainly type 16 and 18) prevalence is noted in 40-45\% of penile cancers in several systematic reviews [130-134]. In a Belgian study, HPV DNA was identified in $61 \%$ of invasive penile cancer samples with the commonest serotypes being HPV 16, 11, 56 and 18 [134]. Importantly, only 13\% of the cases in this study were infected with HPV types present in HPV vaccines.

\section{Level 2 evidence}

In a meta-analysis of 8 studies ( 7 case control, 1 cross sectional study), Larke et al showed that circumcision $<18$ years of age was protective against invasive penile cancer with a odds ratio of 0.33 (95\% CI 0.13-0.83) [133]. In those circumcised as adults the risk of invasive carcinoma was increased (OR 2.71, 95\% CI 0.93-7.94), presumably because surgery was performed for conditions predisposing to penile cancer.

\section{Level 3 evidence}

In a matched case control study, Tsen et al showed that phimosis was a strong risk factor for invasive penile cancer (adjusted OR 16, 95\% CI 4.5-57) [135]. The protective effect of neonatal circumcision was not statistically significant when the analysis was restricted to those who did not have a history of phimosis (OR 0.79, 95\% CI 0.29-2.6) and smoking was a clear identified risk factor (OR 5.9 for $>20$ cigarettes/day). In another population based case control study from Denmark, Madsen et al found that penile cancer was positively associated with measures of high and early sexual activity, genital warts, unprotected sex and penile oral sex [136]. Phimosis (OR 4.9, 95\% CI 1.85- 13.0), but not childhood circumcision ( $\mathrm{p}=0.33$ ) was also found to have a strong association on multivariate analyses. The authors concluded that an unretractable foreskin with HRHPV infection might constitute the single most important risk factor for penile cancer. In a population based case control study by Daling et al, 137 men with penile cancer were compared with 671 controls [137]. Lack of childhood circumcision (OR 2.3, 95\% CI 1.34.1), phimosis (OR 7.4, 95\% CI 3.7-15.0) and cigarette smoking (OR 4.5, 95\% CI 2.0- 
10.1) were identified as risk factors for invasive penile cancer but after excluding patients with phimosis, the analysis did not show a protective effect of childhood circumcision. Level 2c evidence: Indirect evidence of the role MC in preventing penile cancer can be investigated by ecological studies in countries with low circumcision rates. Denmark, with $2 \%$ circumcision prevalence, showed decreasing and lower rates of penile cancer than in the US [138]. However, in a more recent study from Denmark, there was an increase in the incidence of penile cancer from 1 to 1.3 per 100,000 men-years between 1978 and 2008 [139]. In the US, despite a decrease in circumcision rates, a 1.2\% average annual incidence rate decrease has been noted between 1973 and 2003 [140].

Recommendations (MC and penile cancer):

1. Circumcision decreases the risk of penile cancer (Level 2-3).

2. However, given the low incidence of invasive penile cancer, the partial protective effect of MC, and the availability of other preventive strategies like HPV vaccination, condom use and smoking cessation programs, it is difficult to justify universal neonatal circumcision as a preventive strategy for preventing penile cancer (Grade B).

3. Recognition and treatment of phimosis during regular health visits is recommended to decrease the risk of penile cancer (Level 5, Grade D). A genitourinary exam during puberty is recommended to ensure preputial retractibility and hygiene, rule out phimosis and counsel regarding HPV vaccination, safe sexual practices and offer the possibility of circumcision as a preventive measure against STI's while specifying the drawbacks and efficacy of other preventive measures (Grade D).

\section{Circumcision and risk of prostate cancer}

A meta- analysis of case control studies by Taylor et al found an increased RR of prostate cancer in men with a history of STI's [141]. A recent case control study explored the association between circumcision and prostate cancer [142]. In a multivariable analysis, controlling for age, family history, race, history of STI's, number of partners and history of prostatitis, the authors did not find an overall association with circumcision (OR 0.87, 95\% CI 0.74-1.02). A previous case control study from the UK, looking primarily at dietary and sexual history found a borderline association on univariate analysis between circumcision and prostate cancer risk (OR 0.62, 95\% CI 0.39-0.98) [143].

Conclusion (MC and prostate cancer)

- There is no convincing evidence on the protective effect of MC against prostate cancer (Level 3- 4 evidence, Grade B).

\section{Role of the foreskin in sensation and sexual function}

There is ongoing controversy regarding the impact of circumcision on penile sensitivity and sexual satisfaction. It is obvious that the foreskin has sensory nerves, which are lost 
following a circumcision. The primary question is whether this presumed loss of sensation or a possible decrease in glans sensitivity impacts sexual satisfaction in a measurable and consistent way after accounting for several confounders. The timing of circumcision (adult versus neonatal) may also impact this effect. The problem is amplified by the lack of a single objective measure of sensitivity (sensation varying by type and site assessed, ejaculation latency, arousal). In addition, this effect of MC has to be studied both from the men and their male and female partners' perspective. It is hard to extrapolate results of adult MC studies on sexual function and sensation to neonatal circumcision.

\section{Adult circumcision}

\section{Level 1-2 evidence}

A recent meta-analysis included 10 studies with significant heterogeneity and poor methodological quality to assess the impact of MC on sexual function [144]. There were no significant differences in sexual desire, dyspareunia, premature ejaculation, ejaculation latency time or erectile dysfunctions between circumcised and uncircumcised men. A secondary analysis of the Ugandan RCT showed no long-term differences in 4456 men randomized to immediate and delayed circumcision arms who were assessed at 6, 12 and 24 months for sexual desire, satisfaction and erectile dysfunction [145]. Though self-reported, there were some significant differences in penetration and pain on intercourse noted at 6 months favoring uncircumcised men but this difference normalized over the follow-up period. The trial showed that there was a higher improvement in sexual satisfaction in the uncircumcised group compared to the circumcised group. In comparison, another trial from Kenya noted that circumcised men reported increased penile sensitivity and enhanced ease of reaching orgasm with no sexual dysfunction as compared to uncircumcised controls [146]. Sexual dysfunction decreased significantly in both the circumcised and uncircumcised men during follow-up. The 2 trials reported very different baseline sexual dysfunction and in both the uncircumcised group reported improvement in sexual satisfaction over time. The Kenyan RCT showed a reduced risk of any self-reported coital injury in those circumcised compared to uncircumcised men (OR 0.61, 95\% CI 0.54-0.68) [147]. There was a significant decrease in reported penile injuries over follow up even in the control uncircumcised group (decrease from $64 \%$ to $43 \%)$.

\section{Level 3-4 evidence}

In a survey conducted in Denmark, there was no difference in the circumcised and noncircumcised group in current sexual activity but circumcised men were more likely to report orgasm difficulties (Adjusted OR=3.26, 95\% CI 1.05-4.16) [148]. In addition, women partners with circumcised spouses also noted orgasm difficulties (Adjusted OR= 
2.66, 95\% CI 1.07-6.66) and dyspareunia (Adjusted OR 8.45, 95\% CI 3.01-23.74). Another cross-sectional study conducted in Belgium on 1369 men (1059 uncircumcised, 310 circumcised) used a self reported online version of the Self-assessment of Genital Anatomy, and Sexual Function, Male questionnaire (SAGASF-M) to measure 4 dimensions of sexual function [149]. Overall, for the penis as a whole the 2 groups differed in sexual pleasure $(\mathrm{p}=0.044)$ and discomfort/pain $(\mathrm{p}=0.018)$, both favoring the uncircumcised group. The study concluded that circumcision led to a decrease in glans sensitivity and overall penile sensitivity. In another detailed study of fine-touch pressure thresholds in circumcised and uncircumcised men, Sorrells et al noted that the glans of uncircumcised men had significantly lower pressure thresholds compared to circumcised men when adjusted for age, type of underwear and ethnicity [150]. Studies before and after circumcision in the adult population generally do not show any differences in sexual activity and function, though these studies are often hard to interpret because of the small sample size, lack of validated instruments to measure sexual function, self reported outcomes, short follow up times after circumcision and presence of medical indications for circumcision [151-154]. Intravaginal ejaculation latency time (IELT) was measured in 2 multinational studies using a stopwatch and a blinded timer [155, 156]. The significance of IELT as a measure of sexual satisfaction and sensation is debatable as a high IELT may suggest a low sensation and conversely a low IELT may suggest premature ejaculation and eventual lower sexual satisfaction. Circumcision and condom use did not impact IELT in both studies.

\section{Neonatal circumcision}

A single study compared men circumcised in the neonatal period to uncircumcised men with normal and abnormal erectile function and used quantitative somatosensory testing for assessing glans sensation [157]. Circumcised men with or without erectile dysfunction had worse vibration and better pressure thresholds but these differences disappeared when controlled for age, hypertension and diabetes.

\section{Sexual function in partners}

In an analysis of self reported sexual experience in women partners of men who participated in the Ugandan RCT before and after circumcision, Kigozi et al showed no changes in $57 \%$ and improved sexual satisfaction in $40 \%$ [158]. In $25 \%$ of the women who reported better sexual satisfaction, the reason given was related to the male seeking more frequent sex. In a study comparing uncircumcised and circumcised homosexual men as part of the HIM (Health in Men) cohort, Mao et al noted no differences in sexual difficulties or type of anal sex practiced [159]. Men circumcised after infancy were more likely to practice receptive anal sex and had a higher incidence of erection difficulties. 


\section{Conclusion}

- There is lack of any convincing evidence that neonatal circumcision will impact sexual function or cause a perceptible change in penile sensation in adulthood (Level 3-4 evidence, Grade C recommendation).

\section{Medical indications for childhood circumcision}

\section{Pathological phimosis}

Pathologic phimosis is an uncommon pediatric diagnosis (0.6-1.5\% of boys) and is diagnosed by the presence of a whitish, fibrotic preputial ring [160]. This is different from physiological phimosis where gentle retraction during examination will show "flowering" or pouting of the preputial orifice and lack of the cicatricial ring [161-164]. Alternative treatments such as preputioplasty, dorsal slit or steroid therapy can be attempted, but depending on the severity of the scar tissue, circumcision may be the only curative option when true phimosis is diagnosed [165-166].

\section{Genital Lichen sclerosis}

Genital lichen sclerosis (LS) or balanitis xerotica obliterans is a chronic, inflammatory dermatosis of the prepuce and glans penis, which can potentially involve the meatus and urethra. The etiology is unknown and probably multifactorial with a possible autoimmune or infective etiology [167]. The disease tends to be progressive and older children; those with obesity and previous surgery tend to have more severe disease [168]. LS should be suspected when clinical examination reveals a more impressive (than phimosis) thick white ring like cicatrix at the distal preputial ring, associated with white discoloration and plaque formation. A history of secondary phimosis in a child with a previously retractile foreskin and failure of topical steroid therapy is also highly suggestive of LS [168-170]. Overall, the incidence of meatal involvement leading to stenosis is low and estimated to be around $2 \%$ [169, 170]. Meatal or urethral involvement is more likely with a history of previous surgery and was seen in $27 \%$ in the series by Gargollo et al [168].

The incidence of this condition is underestimated and recent evidence suggests that in boys referred with a diagnosis of phimosis the incidence ranges between 10-40\% [169-172]. In a series of 100 boys referred for phimosis, the incidence of LS was $1.8 \%$ under 6 years of age and up to 21\% in those older [171]. In another prospective 10- year study by Kiss et al, the incidence of histologically confirmed LS was $40 \%$, and $93 \%$ of LS patients had a history of secondary phimosis [170]. In another series of consecutive patients from the UK, Yardley et al noted a 34\% incidence of LS in boys who underwent circumcision and an overall 12\% prevalence of LS in boys referred to a specialist for foreskin problems [173]. The pathological diagnosis of LS may not correlate with clinical 
suspicion, suggesting circumcision specimen should be routinely subjected to histological examination to rule out LS [174].

The use of topical steroids in LS is debatable with low response rates and requires close follow up, because disease progression may lead to glans and urethral involvement $[167,170,175]$. Circumcision is usually curative, but some children depending on the degree of involvement may need a meatoplasty, glans resurfacing or urethral reconstruction [168]. If the meatus is clearly involved a meatoplasty is indicated during circumcision. However, if the involvement is doubtful close follow up during the postoperative period and uroflowmetry assessments for up to 2 years may be indicated to rule out stenosis [176]. In addition, secondary to the Koebner phenomenon, recurrent LS may appear along scar lines of previous surgery and the use of topical steroids is an option in the post-operative period [167].

\section{Recurrent urinary tract infections}

Circumcision can be performed as an adjunct or alternative to prophylactic antibiotics in infants with UTI-predisposing urological abnormalities as described in the section on UTIs.

\section{Contraindications of neonatal circumcision}

Neonatal circumcision should be performed on medically stable, term infants without other medical conditions, which require ongoing management or increase risk of surgery. Routine neonatal circumcision should not be carried out in children with congenital anomalies of the penis, including hypospadias or epispadias (Fig 4 \& 5), ventral curvature (Fig 6), penoscrotal webbing (Fig 7), and concealed penis (Fig 8). In some of these conditions, a circumcision can be performed with appropriate technical modifications but this requires a pediatric urological consult. Prior circumcision may not compromise distal hypospadias repair in children. In addition, some children with a hypospadias variant termed megameatus-intact prepuce hypospadias have a normal foreskin and a distal hypospadias only uncovered during a circumcision. [177]. Most of these children with this variant or a distal hypospadias can proceed with a circumcision. However, this requires an ability to recognize the severity of the anomaly and therefore as a general rule, all boys with hypospadias should ideally not have a circumcision, prior to a consultation by a pediatric urologist. Children with blood dyscrasias can undergo circumcision, under appropriate treatment and care [178-179].

\section{Anesthesia for neonatal circumcision}

It is clear that neonatal circumcision must be performed with adequate anesthesia and analgesia [180, 181]. The adverse physiological and behavioral responses of inadequate pain control in neonates is convincing, can lead to potential complications and alter longterm pain responses in the neonate [180-182]. Different methods used for providing 
anesthesia and/or analgesia during circumcision includes general anesthesia, topical anesthetics, penile nerve blocks, oral sucrose-glucose administration, non-nutritive sucking, caudal block and various combinations of the above. In addition, the timing of neonatal circumcision may impact pain scores, with earlier surgery being beneficial [183]. Despite a standardized technique, Neonatal/Infant Pain Scores increased significantly beyond day 8 of life and all neonates beyond 3 weeks of age had a score indicating pain during the procedure.

There are 3 topical anesthetic options currently available: lidocaine-prilocaine $5 \%$ cream (EMLA), tetracaine 4\% gel and liposomal lidocaine 4\% cream. When compared to placebo, crying time was shortened and the heart rate reduced in children who were circumcised under EMLA [184]. The analgesic effect of EMLA takes almost 60 minutes to take effect and alone may not be sufficient to control the pain arising from foreskin removal. Wahlgren et al noted that the depth of penetration is variable with EMLA and increases with application time to approximately $6 \mathrm{~mm}$ after 3-4 hours [185]. Reactions to EMLA included erythema and blanching. Increased methaemoglobin levels secondary to oxidation of hemoglobin by prilocaine metabolites, was found to be within normal limits in two trials of EMLA [185]. Liposomal lidocaine is available in the US and has a shorter onset of action.

Dorsal penile (DPNB) and ring blocks are effective techniques to manage circumcision related pain. Based on a RCT that compared these 2 methods with EMLA for neonatal circumcision, there was no statistical difference in crying time and heart rate between a ring and dorsal penile nerve block while EMLA was less effective [186]. Two other trials comparing EMLA to DPNB also demonstrated significantly lower behavioral distress scores and Neonatal Infant Pain Scale scores in the dorsal nerve block group [187-188]. Cyna et al did not find a difference between caudal blocks and DPNB in a meta-analysis of 5 RCT's comparing these interventions but highlight that the possibility of a motor block, and requirement of anesthesia expertise makes a caudal block less preferable in older ambulatory children [189]. Based on the Cochrane review by BradyFryer, a dorsal penile nerve block is the most effective intervention for circumcision related pain with the caveat that the injection is performed appropriately [180]. A ring block has similar efficacy and may be easier and safer to use. EMLA cream and other topical anesthetics are an option when expertise with penile nerve blocks is not available and ideally should be used in conjunction with a block.

The DPNB is performed by injecting subcutaneously at the 11 and 1 o'clock positions on the dorsum of the penis close to the base of the penis using a 25-gauge needle. It is important to aspirate prior to injection to prevent intracorporeal or dorsal vein injection. A wait time of 5 to 8 minutes is recommended to achieve adequate anesthesia. Warming the lidocaine or injecting slowly can decrease the pain associated with injection. In a series of 3909, DPNB the overall complication rate was $0.18 \%$ [190]. 
Long et al studied the sensory distribution of the penile skin and recommend a ventral infiltration just proximal to the ventral foreskin incision to add to the dorsal nerve block [191].

Although it has been shown that analgesic methods such as oral administration of sucrose, glucose, or parenteral acetaminophen were more effective than placebo, it is widely accepted that these methods are not sufficient as sole measures for relieving the pain associated with circumcision [180, 192]. South et al suggested addition of nonnutritive sucking to DPNB based on a RCT, which showed significantly reduced crying time and salivary cortisol levels [193].

Conclusions for anesthesia and analgesia for neonatal circumcision:

1. A dorsal penile nerve block with a ring block, using proper technique, is the most effective technique to provide anesthesia during a neonatal circumcision (Level 1-2 evidence, Grade A recommendation).

2. Topical local anesthetics alone are inferior to nerve and ring blocks and require an adequate time interval for efficacy and can be used as an adjunct to penile blocks (Level 1-2 evidence, Grade $A$ recommendation).

3. Oral sucrose, non- nutritive sucking, music and other environmental interventions should only be used as an adjunct to these methods (Level 1-3 evidence, Grade A recommendation).

\section{Complications of circumcision}

Neonatal circumcision is a safe surgical procedure that is generally well tolerated. Circumcision complications can vary depending on the surgeon experience, technique used, parental expectation of post circumcision appearance, timing of circumcision, patient anatomic factors, gestational age and the accuracy and degree of reporting. Proper pre-operative assessment and examination recognizing possible complicating factors (webbing, ventral skin deficiency, suprapubic fat pad) and adequate post-operative instructions can prevent the commonest complications.

Neonatal circumcisions are performed in the community by a variety of practitioners and the complication rate is higher than that for procedures carried out in the hospital [194]. In addition, it is well documented that physician ability to self-rate success of a procedure is questionable [195]. When combined with the fact that some of the complications are delayed (e.g. meatal stenosis), there is a high likelihood that the actual complication rate for neonatal circumcisions may be underestimated and constitutes an immense burden to a system where the primary procedure is not covered under universal healthcare.

According to Pieretti et al, almost 5\% of pediatric cases performed at a tertiary institution in the US over a 5-year span, with an estimated cost of $\$ 685,608$ were related 
to complications of newborn circumcision [196]. The most frequent complications were redundant foreskin and meatal stenosis. Kokorowski et al queried the Pediatric Health Information System database from 28 freestanding pediatric hospitals in the US between 2004-2009 and identified those undergoing revision circumcision, non-newborn primary circumcision and lysis of penile adhesions following neonatal circumcision [197]. The study found a $119 \%$ increase in the ratio of revision circumcisions to total male ambulatory procedures during this time period. The median cost for revision circumcision was $\$ 1554$ and a total estimated cost of $\$ 688,46,31$ for the 28 hospitals over 6 years.

\section{Overall complication rates}

A recent systematic review on complications of neonatal and infant circumcisions noted a wide 0 to $16 \%$ (median 2\%) range of adverse events in 16 prospective studies [198]. The same review also found that circumcisions performed in older children were associated with more complications (median 6\%) when compared to those carried out in neonates and infants. A systematic review on safety and efficacy of non-therapeutic MC in 5228 men (15-49 years) showed a 4.8\% incidence of complications [199]. The most common complication was postoperative infection (1.5\%), followed by bleeding (1.3\%). Complication rates in the $3 \mathrm{HIV}$ trials conducted in Africa ranged between 1.7-8\% [5355].

In 1999, the AAP Task Force on Circumcision reported a complication rate of $0.2-0.6 \%$. In contrast, the Canadian Pediatric Society has published complication rates as high as $2 \%$ for neonatal circumcision [200]. Early complications such as bleeding and infection occurred in $0.2 \%$ of 136086 male infants according to a large review [201]. This study only included complications entered on inpatient records and does not provide an estimate of long-term complications. In another US study of 130,475 newborns, conducted in Washington, US, $0.18 \%$ had a bleeding complication after MC [202]. In a trade off analysis the authors calculated that a complication could be expected in one of every 476 circumcisions, that 6 UTI's could be prevented for every complication and about 2 complications would be expected for every case of penile cancer prevented [203]. A review of complication rates following pediatric circumcision in England between 1997- 2003, showed that $1.2 \%$ of boys experienced a short-term complication and another $0.5 \%$ returned to the operating room for a revision within 6 months [3]. Post-circumcision complications can be divided into early and late complications [204211]. Early complications include bleeding, infection, glans necrosis and amputation, delayed/early slippage of circumcision devices and very rarely death. Late complications include inadequate skin removal, cosmetic issues, inclusion cysts, adhesions and skin bridges, suture sinus tracts, ventral curvature, secondary buried penis and phimosis, urethrocutaneous fistulae and meatal stenosis. 


\section{Factors predicting complication rate}

Timing of surgery can be predictive of complications as bleeding related complications are higher in older infants [212]. Penile adhesions and secondary buried penis is more likely in infants with a higher weight for length percentile [213]. The results of varying techniques may also be a possible factor affecting complication rates [209, 214]. Results from a small RCT, which compared 2 surgical techniques (sleeve vs. Plastibell ${ }^{\circledR}$ ) in older children, showed that late complications occurred in $12 \%$ of the cases that used the sleeve technique versus 5\% with the Plastibell ${ }^{\circledR}$ device [214]. Current on- going operator experience was shown to be an important factor in lower bleeding complication rate compared to patient related variables and long-term operator experience [215].

\section{Penile adhesions, secondary phimosis and concealed penis}

These relatively common complications of circumcision are the primary reasons for reoperation in the late post-operative period following a circumcision. They are more likely in those with an increased weight for length percentile, a large supra-pubic fat pad with abnormal dartos attachments to the skin or there is pre-existing peno-scrotal webbing or ventral penile skin deficiency. Topical steroids and occasional dilatation of the prepucial ring and retraction can lead to resolution [216, 217]. In children with a secondary concealed penis, but no phimosis, observation may be an option as the cosmetic appearance tends to improve with age and surgery should be delayed till the child is at least 3 years of age [218]. Adhesions of the mucosal collar to the glans are a common complication and can be prevented by gentle retraction and use of barrier ointments in the early post- operative period [219].

\section{Meatal stenosis}

Meatal stenosis is a common, under-reported complication of circumcision, usually requiring a ventral meatotomy for correction. It is postulated that chronic irritation of the meatus, ammoniacal meatitis and/or division of the frenular artery after circumcision may be predisposing factors. Meatal stenosis can lead to an upwardly deflected urinary stream, dysuria, urgency or difficulty with voiding and a flat uroflow curve. The incidence of asymptomatic meatal stenosis (< 5 Fr meatal caliber) can be as high as $20 \%$ though its clinical significance is debatable [208]. In a review of 1009 circumcised boys who were examined over the age of 3 years of age, Van Howe found an overall $2.8 \%$ incidence of symptomatic meatal stenosis post-neonatal circumcision [207]. Nearly all underwent a meatotomy but the exact number was unavailable. Studies with long-term follow up of circumcision report this complication fairly commonly with the incidence varying between $2.8-11 \%$.

\section{Recommendations:}

1. Complication rates post- neonatal circumcision are usually low (around $2 \%$ ) but given the variability in quoted complication rates and risk of 
delayed complications not treated by the original physician performing the neonatal circumcision it is likely that the overall complication rate is slightly higher (Level 2-4).

2. Operator experience and training, recognition of contraindications to circumcision, technique used, age and patient related variables can impact results and proper reporting and auditing of results is recommended [Level 4, Grade D].

\section{Cost analyses of neonatal circumcision}

The potential impact of routine neonatal circumcision needs to be studied from an economic standpoint as currently parent requested circumcision is not covered under most provincial health plans in Canada. The impact on health service utilization and costs including direct and indirect procedure costs (costs of managing complications and circumcision revision, litigation costs and training costs) have to be weighed against indirect cost savings that may be potentially accrued over time, and balanced against the costs of implementing other preventive strategies.

Sansom et al performed a cost effectiveness analysis of newborn circumcision on reducing a US male's lifetime risk of HIV by applying the results of the African trials. [220]. The number of circumcisions needed to prevent 1 HIV infection was 298 for all males, ranging from 65 for black males to 1231 for white males. Newborn circumcision did not generate cost savings for the white males in the US but was a cost saving intervention for all males, African-Americans and Hispanics. Schoen et al used a thirdparty US payer database to calculate the cost of newborn circumcision in relation to its health benefits [221]. Using a high medically indicated need for post-neonatal circumcision and offsetting costs related to UTI, HIV, balanoposthitis and penile cancer the total lifetime net cost of a neonatal circumcision was 17 . The majority of the cost offset (50\%) was by the cost of requiring a post- neonatal period circumcision and not the actual health benefits of a circumcision. In a contradictory study, by Van Howe, a cost utility analysis did not show circumcision to be cost effective on sensitivity analysis and on Monte Carlo simulation [222]. A recent study analyzed the impact of a reducing circumcision rate in the US on cost implications related to STI's and UTI [223]. Reducing circumcision rates from $79 \%$ to $10 \%$ would increase lifetime direct medical costs by $313 \$$ per foregone circumcision procedure in males.

In a resource rich setting like Canada, with a relatively lower rate of neonatal circumcisions and an increasing HIV infection risk in MSM, an alternative strategy for MSM males would be a potential strategy. Anderson et al created a mathematical transmission model to conduct an economic analysis and considered 4 strategies (circumcision of all MSM at 18 years of age, all MSM 35-44 years, all insertive MSM > 18 years, all MSM > 18 years) [224]. The model predicted a modest 3-5\% decrease in 
HIV infections per year after 25 years of applying these strategies. In the insertive MSM group, 118 circumcisions would need to be performed to prevent $1 \mathrm{HIV}$ infection. In countries with a high HIV infection secondary to heterosexual transmission and low circumcision rates, the cost effectiveness of circumcision is more evident. [225, 226] Even in this setting, McAllister et al calculated the NNT to prevent $1 \mathrm{HIV}$ infection for circumcision as 80 and modeling analysis showed that supplying free condoms was 95 times more cost effective than MC [227].

\section{Training implications}

Neonatal circumcision is performed by family physicians, obstetricians, pediatricians and urologists and this leads to non-standard training methods, varying experience during training and assessment of competency and varying surgical volumes post training. Several simulated training methods have been described using penile models to allow standardized teaching using the Mogen and Gomco clamps [228, 229]. In a survey of obstetric-gynecology residents, 63\% planned to perform neonatal circumcisions, but only $44 \%$ received formal training to do so [230]. When presented with contraindications to circumcision like hypospadias, buried penis and micropenis, the average rate of correctly identified contraindications was a dismal 42\%. Evidence from the Ugandan trial data showed that approximately 100 procedures are needed to gain competence in sleeve circumcision technique [231]. The rate of moderate or severe adverse events showed a statistically significant trend decreasing from $8.8 \%$ for the first 20 procedures to around $2 \%$ beyond 100 . Demaria et al stressed the importance of proper training and follow up and the lack thereof of in the current Canadian health care system with unstructured training and inability to deal with contraindications and complications of neonatal circumcision [232].

\section{Summary of results and recommendations}

The effect of MC has to be analyzed at the individual and societal level. For the individual Canadian neonate, there are definite advantages of a circumcision but the exact estimates of the effect are unknown, the protection provided is not comprehensive, accrue over a life-time and can be achieved by other preventive health measures (Table 2). Evidence therefore, must be analyzed based on its quality and applicability and the GRADE system is an appropriate method to employ when we summarize our results [233]. There are also clear risks associated with this surgical procedure and parents will continue to have to weigh the potential benefits and risks of neonatal circumcision. In an overall societal perspective, given our health care system and the socio-economic and educational status of our population, universal neonatal circumcision is not justified based on the evidence available. 


\section{References}

1. Male circumcision. Task Force on Circumcision. Pediatrics 2012; 130: e756e785.

2. Trends in in-hospital newborn male circumcision- United States, 1999- 2010. ww.cdc.gov/mmwr/preview/mmwrhtml/mm6034a4.htm

3. Cathcart P, Nuttall M, van der Meulen J, et al. Trends in pediatric circumcision and its complications in England between 1997 and 2003. Br J Surg 2006; 93: 885-90.

4. Nelson C, Dunn R, Wan J, et al. The increasing incidence of newborn circumcision: data from the nationwide inpatient sample. J Urol 2005 173: 978-81.

5. Wang M, Macklin E, Tracy E, et al. Updated parental viewpoints on male neonatal circumcision in the United States. Clin Pediatrics. 2010; 49: 131-6.

6. Rediger C, Muller AJ. Parent's rationale for male circumcision. Can Fam Physician 2013; 59: e110-15.

7. 7. Oxford Levels of evidence. www.cebm.net.

8. Gairdner D. The fate of the foreskin. A study of circumcision. Br Med J 1949; 2: 1433-36.

9. T, Chang $\mathrm{CH}$, Chang SS. Foreskin development before adolescence in 2149 school-boys. Int J Urol 2006; 13:968-69.

10. Babu R, Harrison SK, Hutton KA. Ballooning of the foreskin and physiological phimosis: is there any evidence of obstructed voiding? BJU Int 2004; 94:384-7.

11. McGregor TB, Pike JG, Leonard MP. Pathologic and physiologic phimosis: approach to the phimotic foreskin. Can Fam Physician 2007; 53: 445-8.

12. Letendre J, Barrieras D, Franc-Guimond J, et al. Topical triamcinolone for persistent phimosis. J Urol 2009; 182: 1759-64.

13. de Oliveira Pileggi F, Vincente Y. Phimotic ring topical corticoid cream $(0.1 \%$ mometasone furoate) treatment in children. J Pediatr Surg 2007; 42: 1749-52.

14. Lund L, Wai KH, Mui LM, et al. An 18-month follow-up study after randomized treatment of phimosis in boys with topical steroid versus placebo. Scand J Urol Nephrol. 2005; 39:78-81.

15. Nobre YD, Freitas RG, Felizardo MJ, et al. To circ or not to circ: Clinical and pharmacoeconomic outcomes of a prospective trial of topical steroid versus primary circumcision. Int. Braz J Urol. 2010; 36(1): 75-85.

16. Yang SS, Tsai YC, Wu CC, et al. Highly potent and moderately potent topical steroids are effective in treating phimosis: a prospective randomized study. $\mathrm{J}$ Urol 2005; 173:1361-3.

17. Golubovic Z, Milanovic D, Vukadinovic V, et al. The conservative treatment of phimosis in boys. Br J Urol 1996; 78: 786-8.

18. Zavras N, Christianakis E, Mpourikas D, et al. Conservative treatment of phimosis with fluticasone proprionate $0.05 \%$ : a clinical study in 1185 boys. $\mathrm{J}$ of Pediatr Urol, 2009; 5:181-5. 
19. Reddy S, Jain V, Dubey M, et al. Local steroid therapy as the first line treatment for boys with symptomatic phimosis - a long-term prospective study. Acta Paediatr. 2012; 101: 130-3.

20. Ghysel C, Vander Eeckt K, Bogaert G. Long-term efficiency of skin stretching and a topical corticoid cream application for unretractable foreskin and phimosis in prepubertal boys. Urol Int 2009; 82: 81-8.

21. Ku WK, Chiu B, Huen KF. Outcome and recurrence in treatment of phimosis using topical betamethasone in children in Hong Kong. J Paediatr Child Health, 2007; 43:74-9.

22. Ashfield J, Nickel K, Siemens D, et al. Treatment of phimosis with topical steroids in 194 children. J Urol 2003; 169:1106-8.

23. Elmore J, Baker L, Snodgrass W. Tropical steroid therapy as an alternative to circumcision for phimosis in boys younger than 3 years. J Urol 2002; 168:1746-7.

24. Winberg J, Anderson HJ, Bregstom T, et al. Epidemiology of symptomatic urinary tract infection in childhood. Acta Pediatr Scand 1974; 252 (suppl): 1-20

25. Panaretto KS, Craig JC, Knight JF, et al. Risk factors for recurrent urinary tract infection in preschool children. J Paediatr Child Health 1999; 35:454-9.

26. Shaikh N, Morone N, Bost J et al. Prevalence of urinary tract infection in childhood. Pediatr Infect Dis J 2008; 27: 302- 8.

27. Liu C, Hungate BA, Tobian AR, et al. Male circumcision significantly reduces prevalence and load of genital anaerobic bacteria. mBio 2013; 4:1-9.

28. Wiswell TE, Miller GM, Gelston HM Jr, et al. Effect of circumcision status on periurethral bacterial flora during the first year of life. J Pediatr 1988; 113:4426.

29. Fussell EN, Kaack MB, Cherry R, et al. Adherence of bacteria to human foreskins. J Urol 1988; 140: 997-1001.

30. Balat A, Karakok M, Guler E, et al. Local defense systems in the prepuce. Scand J Urol Nephrol 2008; 42: 63-5.

31. Ladenhauf HN, Ardelean MA, Schimke C, et al. Reduced bacterial colonization of glans penis after male circumcision in children - A prospective study. J Pediatr Urol 2013; 9: 1137-44.

32. Bonacorsi S, Lefevre S, Clermont O, et al. Escherichia coli strains causing urinary tract infection in uncircumcised infants resemble urosepsis-like adult strains. J Urol 2005; 173:195-7.

33. Shaikh N, Morone N, Lopez J, et al. Does this child have a urinary tract infection? JAMA 2007; 298 (24) 2895-2904.

34. Singh-Grewal D, Macdessi J, Craig J. Circumcision for the prevention of urinary tract infection in boys: a systematic review of randomized trials and observational studies. Arch Dis Child 2005; 90:853-8.

35. Nayir A. Circumcision for the prevention of significant bacteuria in boys. Pediatr Nephrol 2001; 16: 1129-34.

36. Morris B, Wiswell T. Circumcision and lifetime risk of urinary tract infection: A systematic review and meta-analysis. J Urol 2013; 189: 2118-24. 
37. Jagannath VA, Fedorowicz Z, Sud V, et al. Routine neonatal circumcision for the prevention of urinary tract infections in infancy. The Cochrane Collaboration 2012; 1-12.

38. Zorc J, Levine A, Platt S, et al. Clinical and demographic factors associated with urinary tract infections in young febrile infants. Pediatrics 2005; 116 (3): 644-8.

39. To T, Agha M, Dick P et al. Cohort study on circumcision of newborn boys and subsequent risk of urinary tract infection. The Lancet 1813-16.

40. Craig J, Knight J, Sureshkumar P, et al. Effect of circumcision on incidence of urinary tract infection in preschool boys. J Pediatr 1996; 128: 23-27.

41. Simforoosh N, Tabibi A, Khalili, S, et al. Neonatal circumcision reduces the incidence of asymptomatic urinary tract infection: A large prospective study with long-term follow up using Plastibell. J Pediatr Urol 2012; 8: 320-23.

42. Toker O, Schwartz S, Segal G, et al. A costly covenant: Ritual circumcision and urinary tract infection. IMAJ 2010; 12: 262-65.

43. Prais D, Shoov-Furman R, Amir J. Is ritual circumcision a risk factor for neonatal urinary tract infections? Arch Dis Child 2009; 94:191-4.

44. Alsaywid B, Saleh H, Deshpande A, et al. High grade primary vesicoureteral reflux in boys: Long-term results of a prospective cohort study. J Urol 2010; 184: 1598-1603.

45. Kwak C, Seung-June OH, Lee A, et al. Effect of circumcision on urinary tract infection after successful antireflux surgery. BJU Int 2004; 94: 627-9.

46. Gucuk A, Burgu B, Gokce L, et al. Do antibiotic prophylaxis and/or circumcision change periurethral uropathogen colonization and urinary tract infection rates in boys with VUR? J Pediatr 2013; 1-6.

47. Mukherjee S, Joshi A, Carroll D, et al. What is the effect of circumcision on risk of urinary tract infection in boys with posterior uretheral valves? J Pediatr 2009; 44: 417-21.

48. Zareba P, Lorenzo AJ, Braga LH. Risk factors for febrile urinary tract infection in infants with prenatal hydronephrosis: comprehensive single centre analysis. J Urol 2014; 191: 1614-8.

49. Roth C, Hubanks M, Bright B, et al. Occurrence of urinary tract infection in children with significant upper urinary tract obstruction. J Urol 2009; 73: 74-8.

50. Song SH, Lee SB, Park YS, et al. Is antibiotic prophylaxis necessary in infants with obstructive hydronephrosis? J Urol 2007; 177:1098-101.

51. Wingerter S, Bachur R. Risk factors for contamination of catheterized urine specimens in febrile children. Pediatr Emerg Care 2011; 27: 1-4.

52. Infectious Disease Prevention and Control: Estimates of HIV Prevalence and Incidence in Canada, 2011h. http://webqa.phac-aspc.gc.ca/aidssida/publication/survreport/estimat2011-eng.php.

53. Bailey R, Moses, S, Parker, C et al. Male circumcision for HIV prevention in young men in Kisumu, Kenya: a randomized controlled trial. The Lancet 2007; 369:643-56.

54. Gray R, Kigozi G, Serwadda D, et al. Male circumcision for HIV prevention in med in Rakai, Uganda: a randomized trial. The Lancet 2007; 369:657-66. 
55. Auvert B, Taljaard D, Lagarde E, et al. Randomized, controlled intervention trial of male circumcision for reduction of HIV infection risk: The ANRS 1265 Trial. PLoS Medicine 2005; 2:1112-22.

56. WHO/UNAIDS. New data on male circumcision and HIV prevention: policy and programme implications. Geneva: WHO; 2007.

57. Smith D, Taylor A, Kilmarx P et al. Male circumcision in the United States for the prevention of HIV infection and other adverse health outcomes: report from a CDC consultation. Public Health Records 2010; 125:72-82.

58. Mehta SD, Krieger JN, Agot K, et al. Circumcision and reduced risk of selfreported penile coital injuries: results from a randomized controlled trial in Kisumu, Kenya. J Urol 2010; 184: 203-7.

59. Soto-Ramirez LE, Renjifo B, McLane MF, et al. HIV-1 Langerhans' cell tropism associated with heterosexual transmission of HIV. Science 1996; 271:1291-3.

60. Price LB, Liu CM, Johnson KE, et al. The effects of circumcision on the penis microbiome. PLoS One 2010; 5: e8422.

61. McCoombe SG, Short RV. Potential HIV-1 target cells in the human penis. AIDS 2006; 20: 1491-5.

62. Kigozi G, Wawer M, Ssettuba A, et al. Foreskin surface area and HIV acquisition in Rakai, Uganda (size matters). AIDS 2009; 23: 2209-13.

63. Sobngwi-Tambekou J, Taljaard D, Lissouba P, et al. Effect of HSV-2 Serostatus on acquisition of HIV by young men: results of a longitudinal study in Orange Farm, South Africa. J Infect Dis 2009; 1: 958-63.

64. Gray R, Serwadda D, Tobian A, et al. Effects of genital ulcer disease and herpes simplex virus type 2 on the efficacy of male circumcision for HIV prevention: analyses from the Rakai trials. PLoS 2009; 6: 1-8.

65. Mehta S, Moses S, Parker C et al. Circumcision status and incident herpes simplex virus type 2 infection, genital ulcer disease, and HIV infection. AIDS 2012; 26: 1141-49.

66. Sahasrabuddhe V, Vermund S. The future of HIV prevention: Control of sexually transmitted infections and circumcision interventions. Infect Dis Clin N Am 2007; 21:241-57.

67. Fink AJ. A possible explanation for heterosexual male infection with AIDS. N Engl J Med 1986; 315: 1167.

68. Weiss HA, Quigley MA, Hayes RJ. Male circumcision and risk of HIV infection in sub-Saharan Africa: a systematic review and meta-analysis. AIDS 2000; 14: 2361-70.

69. Warner L, Ghanem K, Newman D, et al. Male circumcision and risk of HIV infection among heterosexual African American men attending Baltimore sexually transmitted disease clinics. J Infect Dis 2009; 1:59-65.

70. Drain PK, Halperin DT, Hughes JP, et al. Male circumcision, religion, and infectious diseases: an ecologic analysis of 118 developing countries. BMC Infect Dis 2006; 6: 172. 
71. Siegfried N, Muller M, Deeks JJ et al. Male circumcision for prevention of heterosexual acquisition of HIV in men (review). The Cochrane Library 2009; 4:1-40.

72. Eaton L, Cain D, Agrawal A et al. The influence of male circumcision for HIV prevention on sexual behavior among traditionally circumcised men in Cape Town, South Africa. Int J STD AIDS 2011; 22:6-674-9.

73. Gray R, Kigorzi G, Kong X et al. The effectiveness of male circumcision for HIV prevention and effects on risk behaviors in a posttrial follow up study. AIDS 2012; 5:609-15.

74. Mattson C, Campbell R, Bailey R et al. Risk compensation is not associated with male circumcision in Kisumu, Kenya: A multi-faceted assessment of men enrolled in a randomized controlled trial. PLoS 2008; 3:1-9.

75. Hall HI, Song R, Kaplan EH, et al. Estimation of HIV incidence in the United States. JAMA 2008; 300: 520-9.

76. Wiysonge CS, Kongnyuy EJ, Shey M, et al. Male circumcision for prevention of homosexual acquisition of HIV in men. Cochrane Database Syst Rev 2011; (6); CD007496.

77. Millett GA, Flores SA, Marks G, et al. Circumcision status and risk of HIV and sexually transmitted infections among men who have sex with men: a meta-analysis. JAMA 2008; 300: 1674-84.

78. Londish GJ, Templeton DJ, Regan DJ, et al. Minimal impact of circumcision on HIV acquisition in men who have sex with men. Sex Health 2010; 7: 46370.

79. Wawer M, Makumbi F, Kigozi et al. Circumcision in HIV-infected men and its effect on HIV transmission to female partners in Rakai, Uganda: a randomized controlled trial. The Lancet 2009; 374: 229-37.

80. Weiss H, Hankins C, Dickson K. Male circumcision and risk of HIV infection in women: a systematic review and meta-analysis. The Lancet 2009; 9: 66977.

81. Baeten J, Donnell D, Kapinga S et al. Male circumcision and risk of male-tofemale HIV-1 transmission: A multinational prospective study in African HIV-1 serodiscordant couples. AIDS 2010; 13: 1-13.

82. Green L, Travis J, McAllister R et al. Male circumcision and HIV prevention insufficient evidence and neglected external validity. Am J Prev Med 2010; 39: 479-82.

83. Newell M-L, Barnighausen T. Male circumcision to cut HIV risk in the general population. Lancet 2007; 369: 617-9.

84. Lie R, Miller F. What counts as reliable evidence for public health policy: the case of circumcision for preventing HIV infection. BMC Med Res Methodol 2011; 11:1-7.

85. Weiss H, Dickson K, Agot K et al. Male circumcision for HIV prevention: current research and programmatic issues. AIDS 2010; 24: S61-8.

86. Mor Z, Kent C, Kohn $\mathrm{R}$ et al. Declining rates in male circumcision amidst increasing evidence of its public health benefit. PLoS 2007; 9: 1-4. 
87. Xu X, Patel D, Dalton V, et al. Can routine neonatal circumcision help prevent human immunodeficiency virus transmission in the United States? Am J Mens Health 2009; 3:79-84.

88. Auvert B, Sobngwi-Tambekou J, Cutler E, et al. Effect of male circumcision on the prevalence of high-risk human papillomavirus in young men: results of a randomized controlled trial conducted in Orange Farm, South Africa. J Infect 2009; Dis 1: 14-19.

89. Tobian A, Serwadda D, Quinn T, et al. Male circumcision for the prevention of HSV-2 and HPV infections and syphilis. N Engl J Med 2009; 13: 12981309.

90. Tobian A, Kong X, Gravitt P, et al. Male circumcision and anatomic sites of penile high-risk human papillomavirus in Rakai, Uganda. Int J Cancer 2011; 12:1-11.

91. Gray R, Serwadda D, Kong X. Male circumcision decreases acquisition and increases clearance of high risk human papillomavirus in HIV-negative men: a randomized trial in Rakai, Uganda. J Infect Dis 2010; 15: 1-14.

92. Serwadda D, Wawer M, Makumbi F, et al. Circumcision of HIV-infected men: effects on high risk human papillomavirus infections in a randomized trial in Rakai, Uganda. J Infect Dis 2010; 201: 1-14.

93. Tobian AA, Kigozi G, Gravitt PE, et al. Human papillomavirus incidence and clearance among HIV-positive and HIV-negative men in sub-Saharan Africa. AIDS 2012; 26: 1555-65.

94. Wilson L, Gravitt P, Tobian A et al. Male circumcision reduces penile highrisk human papillomavirus viral load in a randomized clinical trial in Rakai, Uganda. Sex Transm Infect 2013; 89: 262-66.

95. Weaver BA, Feng Q, Holmes KK, et al. Evaluation of genital sites and sampling techniques for detection of human papillomavirus DNA in men. J Infect Dis 2004; 189:677-85.

96. Larke N, Thomas SL, Dos Santos S et al. Male circumcision and human papillomavirus infection in men: a systematic review and meta-analysis. J Infect Dis 2011; 9: 1375-90.

97. Albero G, Castellsague X, Giuliano A, et al. Male circumcision and genital human papillomavirus: A systematic review and meta-analysis. Sex Transm Dis 2012; 39: 104-13.

98. Dickson N, Ryding J, van Roode T et al. Male circumcision and serologically determined human papillomavirus infection in a birth cohort. Cancer Epidemiol Biomarkers 2009; 18: 177-83.

99. Albero G, Villa L, Lazcano-Ponce E et al. Male circumcision and prevalence of genital human papillomavirus infection in men? A multinational study. BMC Infect Dis2013; 13: 1-10.

100. Poynten I, Jin F, Templeton D et al. Prevalence, incidence and risk factors for human papillomavirus 16 seropositivity in Australian homosexual men. Sex Transm Dis 2012; 39: 726-32. 
101. Wawer M, Tobian A, Kigozi G et al. Effect of circumcision of HIV-negative men on transmission of human papillomavirus to HIV-negative women: a randomized trial in Rakai, Uganda. The Lancet 2011; 377: 209-18.

102. Tobian A, Kong X, Wawer M et al. The effect of circumcision of HIVinfected men on human papillomavirus infection in female partners: Analyses using data from a randomized trial in Rakai, Uganda. Lancet Infect Dis 2011; 8:604-12.

103. Winer RL, Hughes JP, Feng Q, et al. Condom use and the risk of genital human papillomavirus infection in young women. N Engl J Med 2006; 354: 2645-54.

104. Mehta S, Moses S, Agot K et al. Adult male circumcision does not reduce the risk of incident Neisseria gonorrhoeae, Chlamydia trachomatis, or Trichomonas vaginalis infection: results from a randomized, controlled trial in Kenya. J Infect Dis 2009; 8:370-8.

105. Sobngwi-Tambekou J, Taljaard D, Nieuwoudt M, et al. Male circumcision and Neisseria gonorrhoeae, Chlamydia trachomatic and Trichomonas vaginalis: observations after a randomized controlled trial for HIV prevention. Sex Trans Infect 2009; 85: 116-20.

106. Weiss HA, Thomas SL, Munabi SK, et al. Male circumcision and risk of syphilis, chancroid, and genital herpes: a systematic review and meta-analysis. Sex Transm Infect 2006; 82:101-10.

107. Diseker R, Peterman T, Kamb M, et al. Circumcision and STD in the United States: cross sectional and cohort analyses. Sex Transm Inf 2000; 474-9.

108. Sena AC, Miller WC, Hobbs MM, et al. Trichomonas vaginalis infection in male sexual partners: implications for diagnosis, treatment and prevention. Clin Infect Dis 2007; 44: 13-22.

109. Mehta S, Gaydos C, Maclean I, et al. The effect of medical male circumcision on urogenital Mycoplasma genitalium among men in Kisumu, Kenya. Sex Transm Dis 2012; 39: 276-80.

110. Turner A, Morrison C, Padian N, et al. Male circumcision and women's risk of incident chlamydial, gonococcal and trichomonal infections. Sex Transm Dis 2008; 37: 689-95.

111. Tobian A, Quinn T. Herpes simplex virus type 2 and syphilis infections with HIV: an evolving synergy in transmission and prevention. Curr Opin HIV AIDS 2009; 4:294- 99.

112. Powers KA, Poole C, Pettifor AE, et al. Rethinking the heterosexual infectivity of HIV-1: a systematic review and meta-analysis. Lancet Infect Dis 2008; 8: 553-63.

113. Freeman EE, Weiss HA, Glynn JR, et al. Herpes simplex virus 2 infection increases HIV acquisition in men and women: systematic review and metaanalysis of longitudinal; studies. AIDS 2006; 20: 73-83.

114. Barnabas RV, Wasserheit JN, Huang Y, et al. Impact of herpes simplex virus Type-2 on HIV-1 acquisition and progression in an HIV vaccine trial (the Step Study). J Acquir Immune Defic Syndr, 2011; 57: 238-44. 
115. Watson-Jones D, Weiss HA, Rusizoka M, et al. Effect of herpes simplex suppression on incidence of HIV among women in Tanzania. N Engl J Med 2008; 358: 1560-71.

116. Celum C, Wald A, Hughes J, et al. Effect of acyclovir on HIV-1 acquisition in herpes simplex virus 2 seropositive women and men who have sex with men: a randomised, double-blind, placebo-controlled trial. Lancet 2008; 371: 2109-19.

117. Tobian A, Ssempijja V, Kigozi G et al. Incident HIV and herpes simplex virus type 2 infection among men in Rakai, Uganda. AIDS 2009; 23: 1589-94.

118. Tobian A, Charvat B, Ssempijja V, et al. Factors associated with the prevalence and incidence of herpes simplex virus Type-2 infection among men in Rakai, Uganda. J Infect Dis 2009; 199: 945-49.

119. Xu F, Markowiz L, Sternberg M, et al. Prevalence of circumcision and herpes simplex virus Type-2 infection in men in the United States: the national health and nutrition examination survey (NHANES), 1999-2004. Sex Transm Dis 2007; 34: 479-84.

120. Jameson D, Celum Cl, Manhart L, et al. The association between lack of circumcision and HIV, HSV-2 and other sexually transmitted infections among men who have sex with men. Sex Transm Dis 2010; 37:147-52.

121. Dickson N, van Roode T, Herbison P, et al. Circumcision and risk of sexually transmitted infections in a birth cohort. Sex Transm Inf 2008; 383-87.

122. Fergusson D, Boden J, Horwood J. Circumcision status and risk of sexually transmitted infection in young adult males: An analysis of longitudinal birth cohort. Pediatrics 2006; 118:1971-77.

123. Gray R, Kigozi G, Serwadda D, et al. The effects of male circumcision on female partners' genital tract symptoms and vaginal infections in a randomized trial in Rakai, Uganda. Am J Obstet Gynecol 2009; 42.1-42.7.

124. Tobian AA, Kigozi G, Redd AD, et al. Male circumcision and herpes simplex virus type 2 infection in female partners: a randomized trial in Rakai, Uganda. J Infect Dis 2012; 205: 486-90.

125. Jemal A, Siegel R, Ward E, et al. Cancer statistics, 2007. CA Cancer J Clin 2007; 57: 43-66.

126. Pow-Sang MR, Ferreira U, Pow-Sang JM, et al. Epidemology and natural history of penile cancer. Urology 210; 76 ( Suppl 2A): S2-S6.

127. Bleeker M, Heideman D, Snijders P, et al. Penile cancer: epidemiology, pathogenesis and prevention. World J Urol 2009; 27: 141-50.

128. Minhas S, Manseck A, Watya, et al. Penile cancer - prevention and premalignant conditions. Urology 2010; 76 (Suppl 2A): S24-35.

129. Shabbir M, Barod R, Hegarty P, et al. Primary prevention and vaccination for penile cancer. Ther Adv Urol 2013; 5: 161-69.

130. Miralles-Guri C, Bruni L, Cubilla AL, et al. Human papillomavirus prevalence and type distribution in penile carcinoma. J Clin Pathol 2009; 62: 870-8.

131. Dillner J, von Krogh G, Horenblas S, et al. Etiology of squamous cell carcinoma of the penis. Scand J Urol Nephrol 2000; 205:189-93.

132. Parkin DM, Bray F. Chapter 2: The burden of HPV-related cancers. Vaccine 2006; 24 (Suppl 3): 11-25. 
133. Larke N, Thomas SL, dos Santos Silva I, et al. Male circumcision and penile cancer: a systematic review and meta-analysis. Cancer causes control 2011; 22: 1097-1110.

134. D’Hauwers KWM, Depuydt CE, Bogers JJ, et al. Human papillomavirus, lichen sclerosus and penile cancer: A study in Belgium. Vaccine 2012; 30: 6573-77.

135. Tsen HF, Morgenstern H, Mack T, et al. Risk factors for penile cancer: results of a population-based case-control study in Los Angeles County (United States). Cancer Causes Control 2001; 12: 267-77.

136. Madsen BS, van den Brule AJC, Jensen HL, et al. Risk factors for squamous cell carcinoma of the penis - population-based case-control study in Denmark. Cancer Epidemiol Biomarkers 2008; 17(10): 2683-91.

137. Daling J, Madeline M, Johnson L, et al. Penile cancer: importance of circumcision, human papillomavirus and smoking in situ and invasive disease. Int J Cancer 2005; 116:606-16.

138. Frisch M, Friis S, Kjaer SK, et al. Falling incidence of penis cancer in an uncircumcised population (Denmark 1943-90). BMJ 1995; 311: 1471.

139. Baldur-Felskov B, Hannibal CG, Mung C, et al. Increased incidence of penile cancer and high-grade penile intraepithelial neoplasia in Denmark 1978-2008: a nationwide population-based study. Cancer causes control 2012; 23: 273-80.

140. Goodman M, Hernandez B, Shvesov Y. Demographic and pathologic differences in the incidence of invasive penile cancer in the United States, 1995-2003. Cancer Epidemiol Biomarkers 2007; 16(9): 1833-39.

141. Taylor ML, Mainous AG $3^{\text {rd }}$, Wells BJ. Prostate cancer and sexually transmitted diseases: a meta- analysis. Fam Med 2005; 37: 506-12.

142. Wright J, Lin D, Stanford J. Circumcision and the risk of prostate cancer. Cancer, 2011; 118: 4437-43.

143. Ewing P, Bowie C. A case-control study of cancer of the prostate in Somerset and east Devon. British Jour of Cancer 1996; 74:661-66.

144. Tian Y, Liu W, Wang JZ, et al. Effects of circumcision on male sexual functions: a systematic review and meta-analysis. Asian J Androl 2013; 15:662-6.

145. Kigozi G, Watya S, Polist C, et al. The effect of male circumcision on sexual satisfaction and function, results from a randomized trial of male circumcision for human immunodeficiency virus prevention, Rakai, Uganda. BJU Int 2008; 101:65-70.

146. Krieger J, Mehta S, Bailey R, et al. Adult male circumcision: effects on sexual function and sexual satisfaction in Kisumu, Kenya. J Sex Med 2008; 5:261022.

147. Mehta S, Krieger J, Agot K, et al. Circumcision and reduced risk of selfreported penile coital injuries: results from a randomized controlled trial in Kisumu, Kenya. J Urol 2010; 184: 203-7.

148. Frisch M, Lindholm M, Gronbaek M. Male circumcision and sexual function in men and women: a survey-based, cross-sectional study in Denmark. Int J Epidemiol 2011; 40: 1367-81. 
149. Bronselaer G, Schober J, Meyer-Bahlburg H, et al. Male circumcision decreases penile sensitivity as measured in a large cohort. BJU Int 2013; 111:820-27.

150. Sorrells M, Snyder J, Reiss M, et al. Fine-touch pressure thresholds in the adult penis. BJU Int 2007; 99:864-9.

151. Kim D, Pang MG. The effect of male circumcision on sexuality. BJU Int 2006; 99:619-22.

152. Collins S, Upshaw J, Rutchik S et al. Effects of circumcision on male sexual function: debunking a myth? J Urol 2002; 167: 2111-12.

153. Peterson A. Elective, adult circumcision does not affect patient perception of sexual health as defined by the Male Sexual Questionnaire (MSHQ) 2010; JMH 7(4): 368-72.

154. Senkul T, Iseri C, Sen B, et al. Circumcision in adults: effect on sexual function. Journal of Urology 2004; 63(1): 155-8.

155. Waldinger M, Quinn P, Dilleen M, et al. A multinational population survey of intravaginal ejaculation latency time. J Sex Med 2005; 2: 492-7.

156. Waldinger M, McIntosh J, Schweitzer D. A five-nation survey to assess the distribution of the intravaginal ejaculatory latency time among the general male population. J Sex Med 2009; 6: 2888-95.

157. Bleustein C, Fogarty J, Eckholdt H, et al. Effect of neonatal circumcision on penile neurologic sensation. J Urol 2005; 65(4): 773-7.

158. Kigozi G, Lukabwe I, Kagaayi J, et al. Sexual satisfaction of women partners of circumcised men in randomized trial of male circumcision in Rakai, Uganda. BJU Int 2009; 104:1698-1701.

159. Mao L, Templeton DJ, Crawford J, et al. Does circumcision make a difference to the sexual experience of gay men? Findings from the Health in Men (HIM) cohort. J Sex Med 2008; 5: 2557-61.

160. Shankar KR, Rickwood AM. The incidence of phimosis in boys. BJU Int 1999; 84: 101-2.

161. McGregor T, Pike J, Leonard M. Pathologic and physiologic phimosis. Approach to the phimotic foreskin. Can Fam Physician, 2007; 53:445-8.

162. Metcalfe P. Foreskin management. Can Fam Physician 2010; 56(8): 290-95.

163. Kayaba H, Tamura H, Kitajima S, et al. Analysis of shape and retractabity of the prepuce in 603 Japanese boys. J Urol 1996; 156: 1813-5.

164. Malone P, Steinbrecher H. Medical aspects of male circumcision. BMJ 2007; 335: 1206-90.

165. Rickwood AMK. Medical indications for circumcision. BJU Int 1999; 83: 4551.

166. Hutcheson J. Male neonatal circumcision: indications, controversies and complications. Urol Clin N Am 2004; 31: 461-7.

167. Clouston D, Hall A, Lawrenschuk N. Penile lichen sclerosus (balanitis xerotica obliterans). BJU Int 2011; 108 (Suppl 2): 14-19.

168. Gargollo P, Kozakewich H, Bauer S. et al. Balanitis xerotica obliterans in boys. J Urol 2005; 174: 1409-12.

169. Becker K. Lichen Schlerosus in boys. Dtsch Arztebl Int 2011; 108 (4): 53-8. 
170. Kiss A, Kiraly L, Kutasy B, et al. High incidence of balanitis xerotica obliterans in boys with phimosis: prospective 10-year study. Pediatric Dermatology 2005; 22 (4): 305-8.

171. Meuli M, Briner J, Hanimann B, et al. Lichen sclerosus et atrophicus causing phimosis in boys: a prospective study with 5- year follow up after complete circumcision. J Urol 1994; 152: 987-9.

172. Mattioli G, Repetto P, Carlini C, et al. Lichen sclerosus et atrophicus in children with phimosis and hypospadias. Pediatr Surg Int 2002; 18: 273-5.

173. Yardley IE, Cosgrove C, Lambert AW. Paediatric preputial pathology: are we circumcising enough? Ann R Coll Surg Engl 2007; 89: 62-5.

174. Bochove-Overgaauw DM, Gelders W, de Vylder AMA. Routine biopsies in pediatric circumcision: (non) sense? J Pediatr Urol 2009; 5: 178-80.

175. Vincent MV, Mackinnon E. The response of clinical balanitis xerotica obliterans to the application of topical steroid-based creams. J Pediatr Surg 2005; 40: 709-12.

176. Holbrook C, Tsang T. management of boys with abnormal appearance of meatus at circumcision for balanitis xerotica obliterans. Ann R Coll Surg Engl 2011; 93; 482-4.

177. Snodgrass W, Khavari R. Prior circumcision does not complicate the repair of hypospadias with an intact prepuce. J Urol 2006; 176: 296-8.

178. Rodriguez V, Titapiwatanakun R, Moir C, et al. To circumcise or not to circumcise? Circumcision in patients with bleeding disorders. Haemophilia 2009; 16:272-76.

179. Kenet G, Chan AKC, Soucie JM, et al. Bleeding disorders in neonates. Haemophilia 2010; 16:168-75.

180. Brady-Fryer B, Wiebe N, Lander J. Pain relief for neonatal circumcision. Intervention Review 2009; 1-113.

181. Lehr V, Taddio A. Topical anesthesia in neonates: clinical practices and practical considerations. Seminars in Perinatology 2007; 323-9.

182. Taddio A, Goldbach M, Ipp M, et al. Effect of neonatal circumcision on pain responses during vaccination in boys. Lancet 1995; 345:291-2.

183. Banieghbal B. Optimal time for neonatal circumcision: an observation-based study. J Pediatr Urol 2009; 5; 359-62.

184. Taddio A, Stevens B, Craig K, et al. Efficacy and safety of lidocaine-prilocaine cream for pain during circumcision. N Engl J Med 1997; 336: 1197-201.

185. Wahlgren CF, Quiding H. Depth of cutaneous analgesia after application of a eutectic mixture of the local anesthetics lidocaine and prilocaine (EMLA cream). J Am Acad Dermatol 2000; 42: 584-8.

186. Lander J, Brady-Fryer B, Metcalfe JB, et al. Comparison of ring block, dorsal penile nerve block, and topical anesthesia for neonatal circumcision: a randomized clinical trial. JAMA 1997; 278: 2157-62.

187. Butler-O’Hara M, LeMoine C, Guillet R. Analgesia for neonatal circumcision: a randomized controlled trial of EMLA cream versus dorsal penile nerve block. Pediatrics 1998; 101:E5. 
188. Howard CR, Howard FM, Fortune K, et al. A randomized, controlled trial of a eutectic mixture of local anesthetic cream (lidocaine and prilocaine) versus penile nerve block for pain relief during circumcision. Am J Obstet Gynecol 1999; 181: 1506-11.

189. Cyna A, Middleton P. Caudal epidural block versus other methods of postoperative pain relief for circumcision in boys. Intervention Review; Cochrane Database Syst Rev, 2008, 1-35.

190. Soh C, Ng S, Lim S. Dorsal penile nerve block. Paediatric Anaesthesia 2003; 13:329-33.

191. Long R, McCartan D, Cullen I, et al. A preliminary study of the sensory distribution of the penile dorsal and ventral nerves: implications for effective penile block for circumcision. BJU Int 2009; 105:1576-8.

192. Stevens B, Yamada J, Ohlsson A. Sucrose for analgesia in newborn infants undergoing painful procedures (Review). Intervention Review 2010; 1-112.

193. South M, Strauss R, South A, et al. The use on non-nutritive sucking to decrease the physiologic pain response during neonatal circumcision: a randomized controlled trial. Am J Obs Gynecol 2005; 193:537-43.

194. Shah T, Raistrick J, Taylor I, et al. A circumcision service for religious reasons. BJU Int. 1999; 83(7): 807-9.

195. Davis DA, Mazmanian PE, Fordis M, et al. Accuracy of physician selfassessment compared with observed measures of competence: a systematic review. JAMA 2006; 296: 1094-102.

196. Pieretti R, Goldstein A, Pieretti-Vanmarcke R. Late complications of newborn circumcision: a common and avoidable problem. Pediatr Surg Int 2010; 26: 515-18.

197. Kokorowski P, Routh J, Hubert K et al. Trends in revision circumcision at pediatric hospitals. Clinical Pediatrics 2013; 1-8.

198. Weiss H, Larke N, Halperin D, et al. Complications of circumcision in male neonates, infants and children: a systematic review. BMC Urol 2010; 10:1-13.

199. Perera CL, Bridgewater FH, Thavaneswaran P, et al. Safety and efficacy of nontherapeutic male circumcision: a systematic review. Ann Fam Med. 2010; 8(1): 64-72.

200. Neonatal circumcision revisited. Fetus and Newborn Committee, Canadian Paediatric Society. CMAJ. 1996; 154(6): 769-80.

201. Williams N, Kapila L. Complications of circumcision. Br J Surg. 1993; 80: 1231-6.

202. Wiswell TE, Geschke DW. Risks from circumcision during the first month of life compared with those for uncircumcised boys. Pediatrics. 1989; 83: 1011-5.

203. Christakis DA, Harvey E, Zerr DM, et al. A trade-off analysis of routine newborn circumcision. Pediatrics 2000; 105:246-9.

204. Krill A, Palmer L, Palmer J. Complications of circumcision. Scientific World Journal 2011; 11: 2458-68.

205. Neonatal herpes simpex virus infection following Jewish ritual circumcisions that included direct orogenital suction - New York City, 2000-2011. MMWR 2012; 61: 405-509. 
206. Joudi M, Fathi M, Hiradfar M. Incidence of asymptomatic meatal stenosis in children following neonatal circumcision. J Pediatr Urol. 2010; 17.

207. Van Howe R. Incidence of meatal stenosis following neonatal circumcision in a primary care setting. Clinical Pediatrics 2006; 49-54.

208. Yegane R, Kheirollahi A, Salehi N, et al. Late complications of circumcision in Iran. Pediatr Surg Int 2006; 22: 442-5.

209. Mousavi S, Salehifar E. Circumcision complications associated with the Plastibell device and conventional dissection surgery: A trial of 586 infants of ages up to 12 months. Adv Urol 2008; 4:1-8.

210. Bode C. O, Ikhisemojie S, Ademuyiwa A.O. Penile injuries from proximal migration of the Plastibell circumcision ring. J Pediatr Urol 2010; 6:23-7.

211. Eroglu E, Bastian O, Ozkan H, Yorukalp O, et al. Buried penis after newborn circumcision. J Urol 2008; 181: 1841-3.

212. Horowitz M, Gershbein AB. Gomco circumcision: when is it safe? J Pediatr Surg 2001; 36: 1047-9.

213. Storm DW, Baxter C, Koff SA, et al. The relationship between obesity and complications after neonatal circumcision. J Urol 2011; 186: 1638-41.

214. Bastos Netto JM, de Araújo JG Jr, de Almeida Noronha MF, et al. Prospective randomized trial comparing dissection with Plastibell ${ }^{\circledR}$ circumcision. J Pediatr Urol. 2010; 6(6): 572-7.

215. Feinberg A, Brust R, Walker T. Bleeding at circumcision: Patient or operator issue? Clinical Pediatrics 2010; 49: 760-3.

216. Palmer J, Elder J, Palmer L. The use of betamethasone to manage the trapped penis following neonatal circumcision. J Urol 2005; 174: 1577-8.

217. Blalock H. J, Vemulakonda V, Ritchey M, et al. Outpatient management of phimosis following newborn circumcision. J Urol 2003; 169: 2332-4.

218. Griffiths DM, Atwell JD, Freeman NV. A prospective survey of the indications and morbidity of circumcision in children. Eur Urol 1985; 11: 184-7.

219. Stenram A, Malmfors G, Okmian L. Circumcision for phimosis- indications and results. Acta Paediatr Scand 1986; 75: 321-3.

220. Sansom S, Prabhu V, Hutchinson A, et al. Cost-effectiveness of newborn circumcision in reducing lifetime HIV risk among US males. PLoS 2010; 5:17.

221. Schoen E, Colby C, To T. Cost analysis of neonatal circumcision in a large health maintenance organization. J Urol 2006; 175: 1111-5.

222. Van Howe R. A cost-utility analysis of neonatal circumcision. Medical Decision Making 584-601.

223. Kacker S, Frick K, Gaydos C, et al. Cost and effectiveness of neonatal male circumcision. Arch Pediatr Adolesc Med 2012; 166: 910-18.

224. Anderson J, Wilson D, Templeton D, et al. Cost-effectiveness of adult circumcision in a resource-rich setting for HIV prevention among men who have sex with men. J Infect Dis 2009; 200: 1803-12.

225. Binagwaho A, Pegurri E, Muita J, et al. Male circumcision at different ages in Rwanda: A cost effectiveness study. PLoS 2010; 7:1-10. 
226. Kahn J, Marseille E, Auvert B. Cost-effectiveness of male circumcision for HIV prevention in a South African setting. PLoS 2006; 3: 2349-58.

227. McAllister R, Travis J, Bollinger D. The cost to circumcise Africa. J Mens Health 2008; 7:307-16.

228. Roca P, Alvarado C, Stausmire J, et al. Effectiveness of a simulated training model for procedural skill demonstration in neonatal circumcision. Simul Healthc 2012; 7: 362-73.

229. Freeman J, Dobbie A. Neonatal circumcision model and competency evaluation for family medicine residents. Family medicine 2007; 39: 241-43.

230. Le B, Mickelson J, Gossett D, et al. Residency training in neonatal circumcision: A pilot study and needs assessment. J Urol 2010; 184: 1754-57.

231. Kiggundu V, Watya S, Kigorzi G et al. The number of procedures required to achieve optimal competency with male circumcision: findings from a randomized trial in Rakai, Uganda. BJU Int 2009; 104: 529-32.

232. Demaria J, Abdulla A, Pemberton J, et al. Are physicians performing neonatal circumcisions well-trained? Can Urol Assoc J 2013; 7:26-4.

233. Guyatt GH, Oxman AD, Vist GE, et al. GRADE: an emerging consensus on rating quality of evidence and strength of recommendations. BMJ 2008; 336: 924-6. 
Figures and Tables

Fig 1. Pathological phimosis.

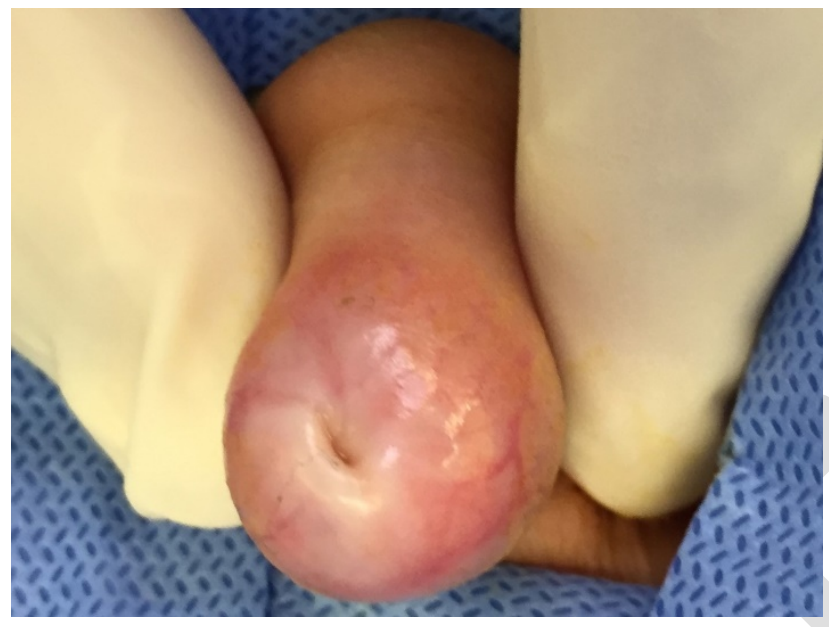

Fig 2. Balano-posthitis.

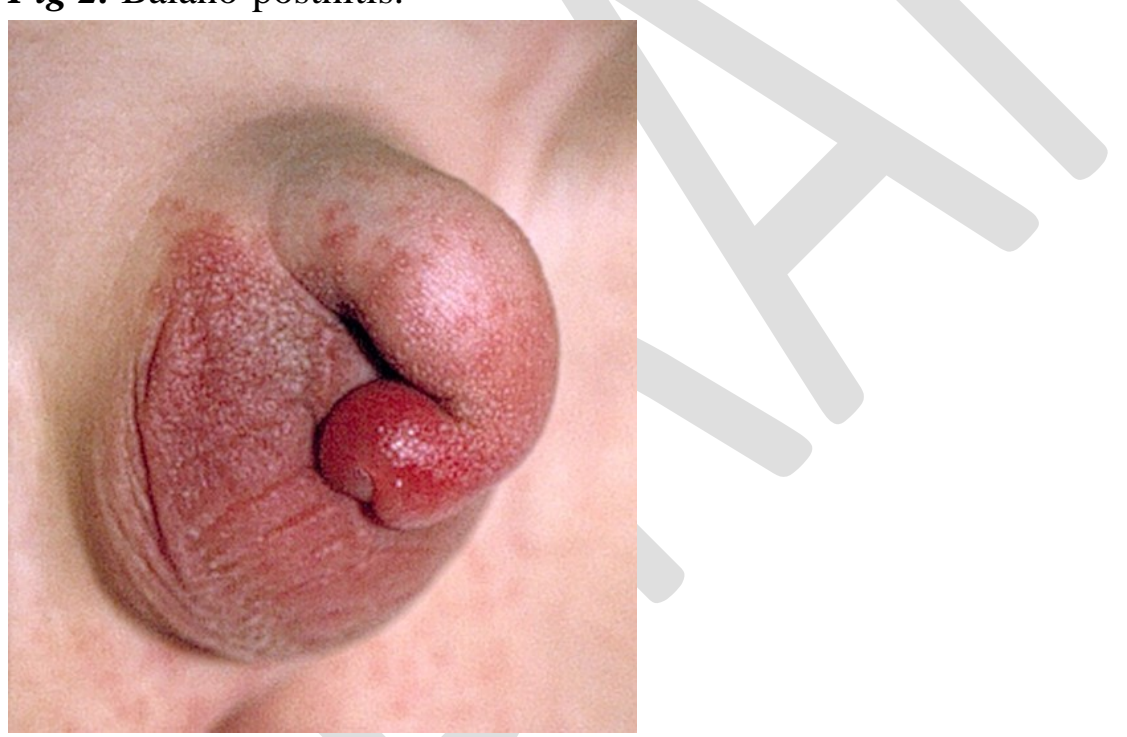


Fig 3. Lichen sclerosus of the foreskin.

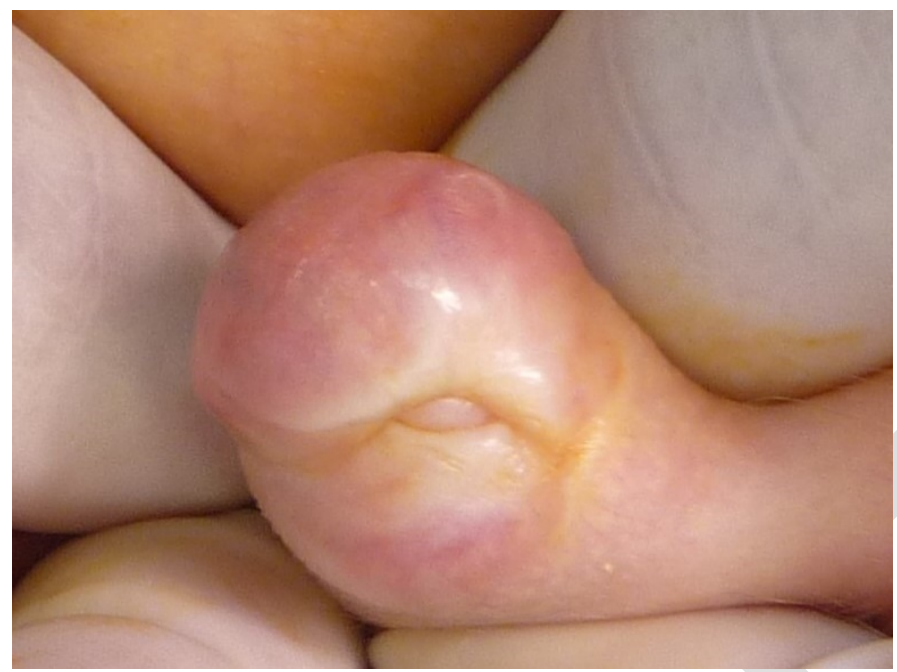

Fig 4. Hypospadias .

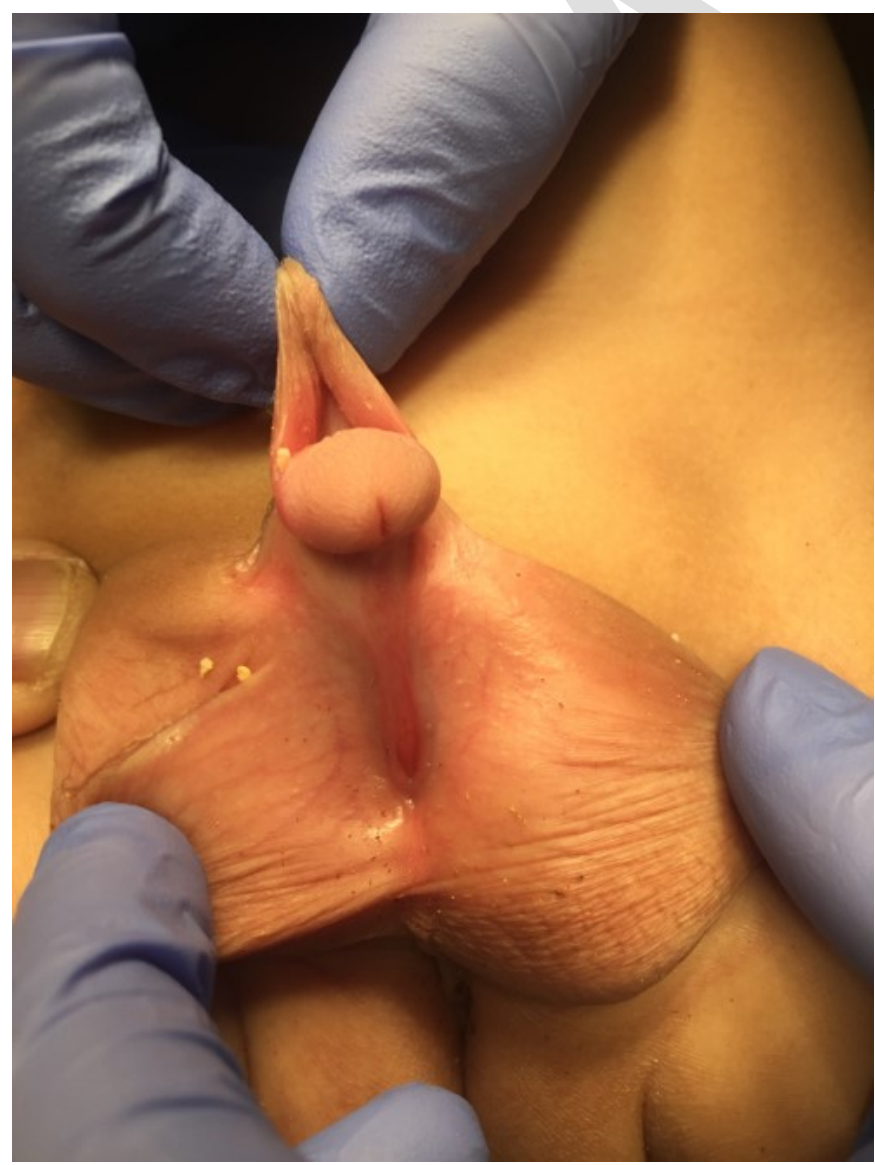


Fig 5. Epispadias.

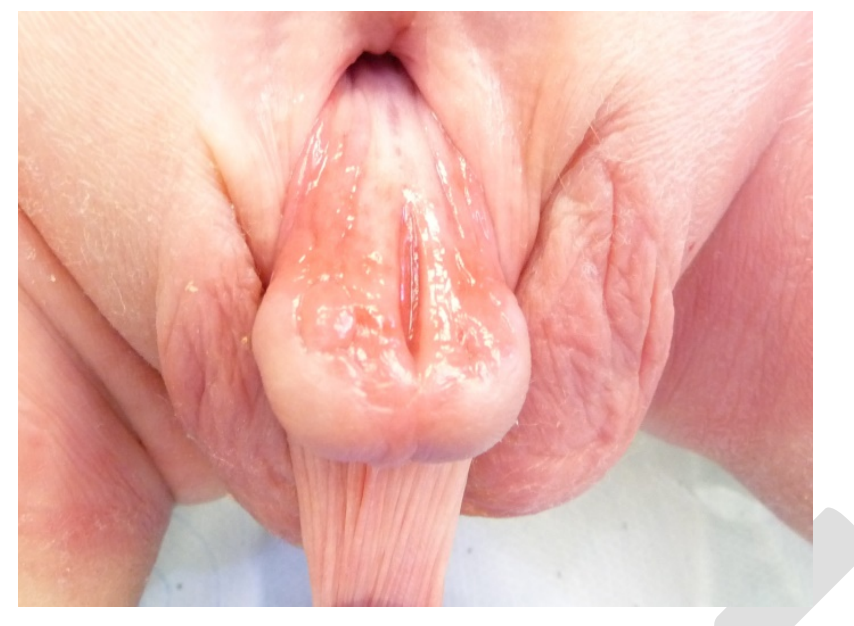

Fig 6. Peno-scrotal webbing.

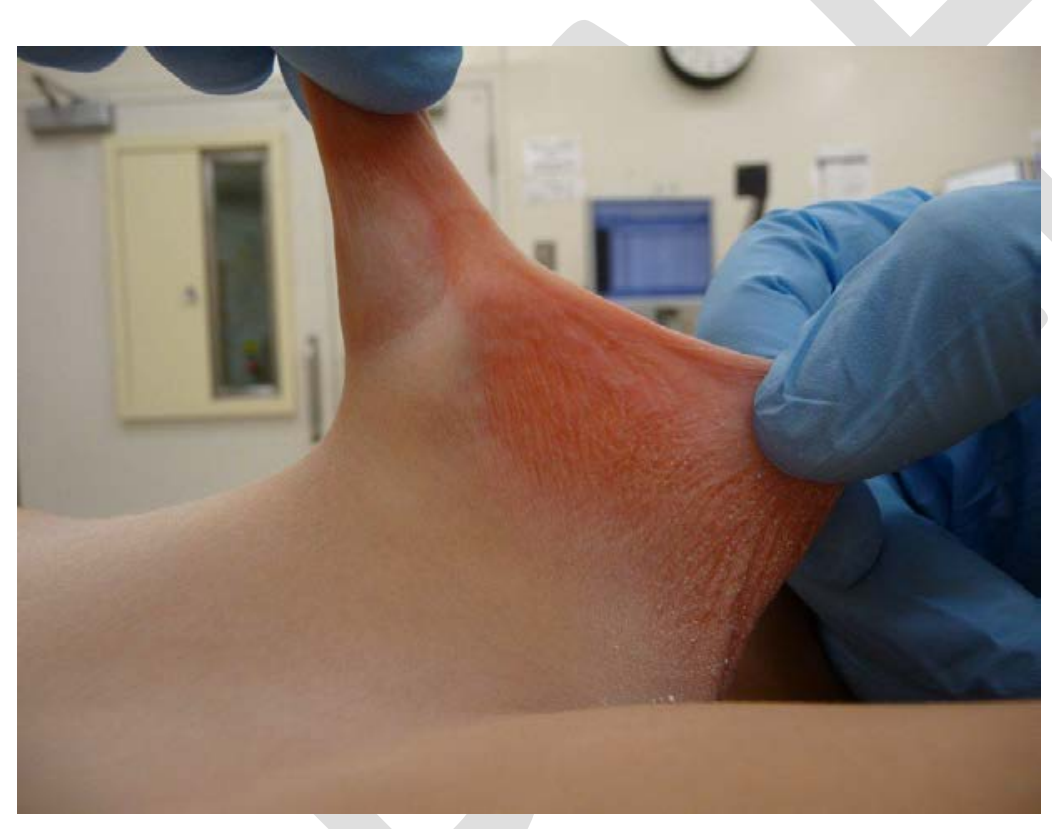


Fig 7. Concealed penis.

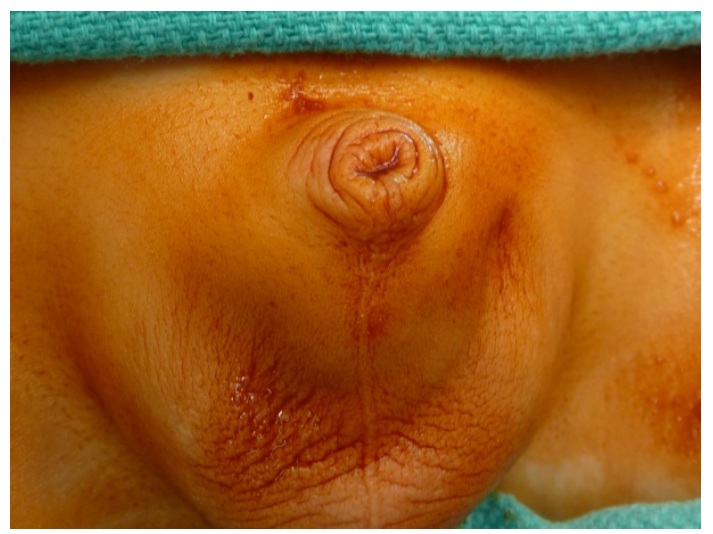

Fig 8. Ventral curvature.

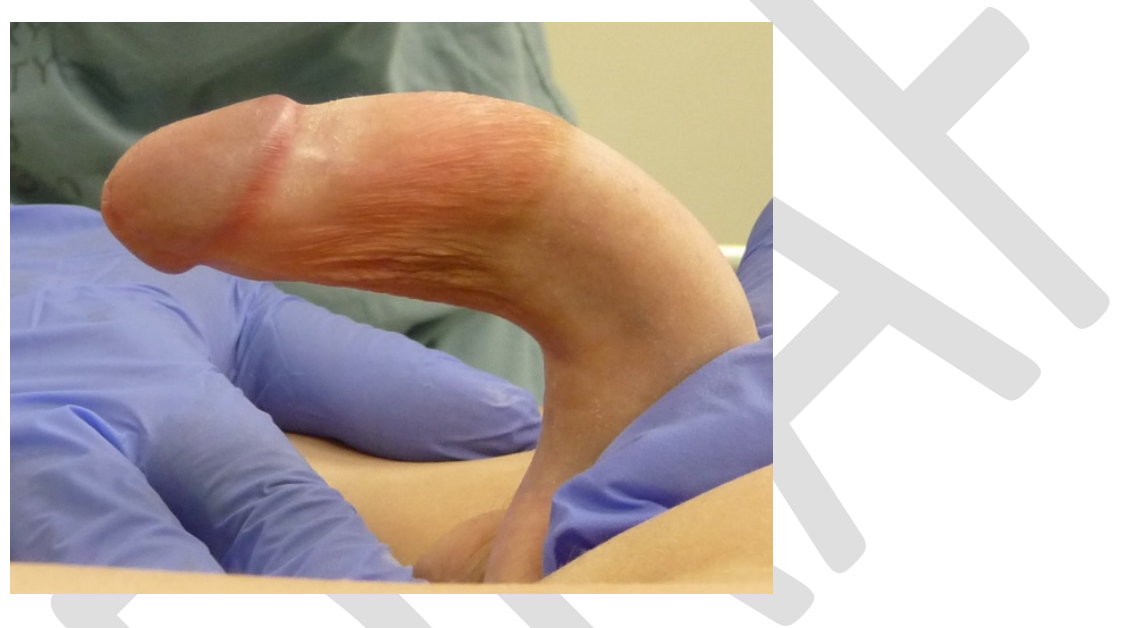

Fig 9. Megameatus intact prepuce hypospadias variant.

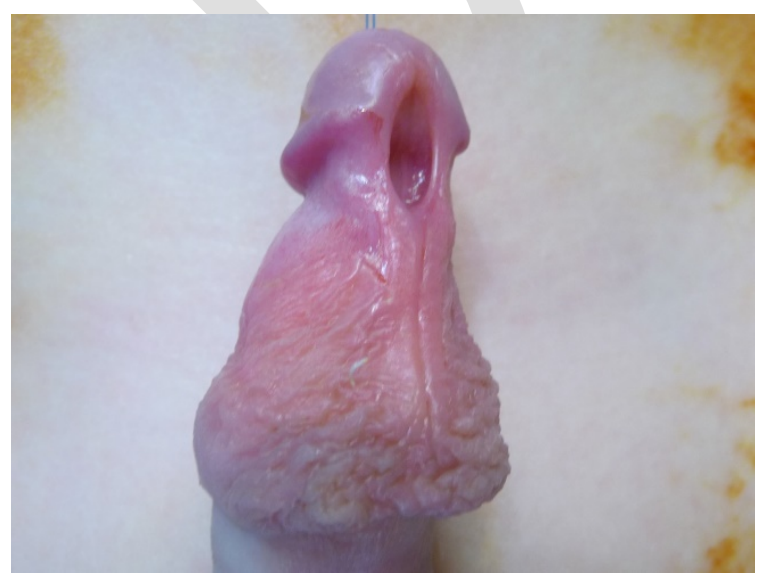




\begin{tabular}{|c|c|c|c|c|c|c|c|c|c|c|c|}
\hline $\begin{array}{l}\text { Study } \\
\text { (location, } \\
\text { time } \\
\text { period) }\end{array}$ & $\begin{array}{c}\text { Allocation } \\
\text { concealment }\end{array}$ & Blinding & $\begin{array}{c}\text { Inclusion } \\
\text { criteria }\end{array}$ & $\mathbf{n}$ & Followup & $\begin{array}{c}\text { Lost to } \\
\text { followup }\end{array}$ & AEs & Outcomes & $\begin{array}{l}\text { ITT RR } \\
(95 \% \text { CI) }\end{array}$ & $\begin{array}{c}\text { As treated } \\
\text { RR } \\
(95 \% \mathrm{CI})\end{array}$ & $\begin{array}{c}\text { Covariate } \\
\text { adjusted } \\
\text { RR }\end{array}$ \\
\hline $\begin{array}{l}\text { Auvert et } \\
\text { al (South } \\
\text { Africa, } \\
2002- \\
2005 \text { ) }\end{array}$ & Partial & $\begin{array}{c}\text { Study } \\
\text { personnel }\end{array}$ & $\begin{array}{c}\text { Male 18-24, } \\
\text { wishing to } \\
\text { be } \\
\text { circumcised }\end{array}$ & 3274 & $\begin{array}{l}\text { Stopped at } \\
63 \% \text { of } \\
\text { total } \\
\text { anticipated } \\
\text { person- } \\
\text { years }\end{array}$ & $\begin{array}{c}251(8 \%) \\
30 \% \text { in } \\
\text { circumcised } \\
\text { and } 33 \% \\
\text { uncircumcised }\end{array}$ & $3.8 \%$ & $\begin{array}{l}\text { Intervention: 20/1546 } \\
\text { Control: 49/1582 }\end{array}$ & $\begin{array}{c}0.42 \\
(0.25-0.70)\end{array}$ & $\begin{array}{c}0.24 \\
(0.14-0.44)\end{array}$ & $\begin{array}{c}0.39 \\
(0.23-0.66)\end{array}$ \\
\hline $\begin{array}{l}\text { Bailey et } \\
\text { al (Kenya, } \\
2002- \\
2006)\end{array}$ & Unclear & $\begin{array}{l}\text { HIV testers } \\
\text { Nurses } \\
\text { counselling } \\
\text { and doing } \\
\text { questionnaires } \\
\text { partially } \\
\text { blinded }\end{array}$ & $\begin{array}{c}\text { HIV- } \\
\text { negative, } \\
\text { 18-24 years }\end{array}$ & 2784 & $\begin{array}{c}\text { Stopped at } \\
87 \% \\
\text { followup }\end{array}$ & $\begin{array}{c}86 \%(1501) \\
\text { completed } 24 \\
\text { month } \\
\text { followup, } \\
\text { overall } \\
1283 / 2784 \\
\text { (46\%) did not } \\
\text { complete trial }\end{array}$ & $1.7 \%$ & $\begin{array}{c}\text { Intervention: 22/1388 } \\
\text { Control: 47/1392 }\end{array}$ & $\begin{array}{c}0.47 \\
(0.28-0.78)\end{array}$ & $\begin{array}{c}0.45 \\
(0.27-0.76)\end{array}$ & $0.44-0.47$ \\
\hline $\begin{array}{l}\text { Gray et al } \\
\text { (Uganda } \\
2002- \\
2006 \text { ) }\end{array}$ & Partial & None specified & $\begin{array}{c}\text { HIV- } \\
\text { negative, } \\
\text { 15-49 years }\end{array}$ & 4996 & $\begin{array}{c}\text { Stopped at } \\
72 \% \\
\text { person- } \\
\text { time } \\
\text { accrual }\end{array}$ & $\begin{array}{c}22 \% \text { at } 24 \\
\text { months } \\
\text { followup }\end{array}$ & $8 \%$ & $\begin{array}{c}\text { Intervention: 22/2387 } \\
\text { Control: 45/2430 }\end{array}$ & $\begin{array}{c}0.49 \\
(0.28-0.84)\end{array}$ & $\begin{array}{c}0.45 \\
(0.25-0.78)\end{array}$ & $\begin{array}{c}0.49 \\
(0.29-0.81)\end{array}$ \\
\hline
\end{tabular}

AE: adverse events; CI: confidence interval; ITT: intention-to-treat; RR: relative risk. 
Guideline: Foreskin care and neonatal circumcision

\begin{tabular}{|l|c|c|c|c|c|}
\hline \multicolumn{7}{|l|}{ Table 2. Benefits of circumcision classified by GRADE recommendations } \\
\hline $\begin{array}{l}\text { Clinical } \\
\text { benefit }\end{array}$ & $\begin{array}{c}\text { Direction of } \\
\text { evidence }\end{array}$ & $\begin{array}{c}\text { Amount of } \\
\text { effect }\end{array}$ & $\begin{array}{c}\text { Level of } \\
\text { evidence }\end{array}$ & $\begin{array}{c}\text { GRADE } \\
\text { quality of } \\
\text { evidence }\end{array}$ & $\begin{array}{c}\text { GRADE } \\
\text { strength of } \\
\text { recommendation }\end{array}$ \\
\hline $\begin{array}{l}\text { Decreased } \\
\text { risk of UTI }\end{array}$ & Positive & $0.07-0.23$ & Level 2 & Low quality & Weak \\
\hline $\begin{array}{l}\text { Decreased } \\
\text { risk of HIV }\end{array}$ & Positive & $0.34-0.62$ & Level 1 & High quality & Strong* \\
\hline $\begin{array}{l}\text { Decreased } \\
\text { risk of HPV } \\
\text { prevalence }\end{array}$ & Positive & $0.57-0.77$ & Level 1 & $\begin{array}{c}\text { Moderate } \\
\text { quality }\end{array}$ & Weak \\
\hline $\begin{array}{l}\text { Decreased } \\
\text { risk of HPV } \\
\text { incidence }\end{array}$ & Unclear & NS & Level 2 & Low quality & Weak \\
\hline $\begin{array}{l}\text { Decreased } \\
\text { risk of HSV }\end{array}$ & Positive & $0.36-0.91$ & Level 2 & Moderate \\
\hline $\begin{array}{l}\text { Decreased } \\
\text { risk of penile } \\
\text { cancer }\end{array}$ & Positive & $0.13-0.83$ & Level 2 & Low quality & Weak \\
\hline
\end{tabular}

${ }^{*}$ Concerns related to external validity of data for Canadian population. HPV: human papilloma virus; HSV: herpes simplex virus; UTI: urinary tract infection. 


\begin{tabular}{|c|c|c|c|c|c|}
\hline $\begin{array}{l}\text { Clinical } \\
\text { benefit }\end{array}$ & $\begin{array}{c}\text { Direction of } \\
\text { evidence }\end{array}$ & $\begin{array}{c}\text { Amount of } \\
\text { effect }\end{array}$ & $\begin{array}{l}\text { Level of } \\
\text { evidence }\end{array}$ & $\begin{array}{l}\text { GRADE } \\
\text { quality of } \\
\text { evidence }\end{array}$ & $\begin{array}{c}\text { GRADE } \\
\text { strength of } \\
\text { recommendation }\end{array}$ \\
\hline $\begin{array}{l}\text { Decreased } \\
\text { risk of UTI }\end{array}$ & Positive & $0.07-0.23$ & Level 2 & Low quality & Weak \\
\hline $\begin{array}{l}\text { Decreased } \\
\text { risk of HIV }\end{array}$ & Positive & $0.34-0.62$ & Level 1 & High quality & Strong $^{*}$ \\
\hline $\begin{array}{l}\text { Decreased } \\
\text { risk of HPV } \\
\text { prevalence } \\
\end{array}$ & Positive & $\begin{array}{c}0.57-0.77 \\
\text { Prevalence } \\
\text { rate ratio } \\
\end{array}$ & & $\begin{array}{c}\text { Moderate } \\
\text { quality }\end{array}$ & Weak \\
\hline $\begin{array}{l}\text { Decreased } \\
\text { risk of HPV } \\
\text { incidence }\end{array}$ & Unclear & NS & Level 2 & Low quality & Weak \\
\hline $\begin{array}{l}\text { Decreased } \\
\text { risk of HSV }\end{array}$ & Positive & $0.36-0.91$ & Level 2 & $\begin{array}{c}\text { Moderate } \\
\text { quality }\end{array}$ & Weak \\
\hline $\begin{array}{l}\text { Decreased } \\
\text { risk of } \\
\text { penile } \\
\text { cancer }\end{array}$ & Positive & 0.13-0.83 & Level 2 & Low quality & Weak \\
\hline
\end{tabular}

${ }^{*}$ Uncertainty related to: 1) effects of neonatal circumcision in Canadian setting; 2)

whether circumcision represents a wise use of resources compared to other preventive strategies; 3) the balance of advantages versus risks of circumcision given the uncertainty of circumcision risks. HPV: human papilloma virus; HSV: herpes simplex virus; UTI: urinary tract infection. 